to appear in the Astrophysical Journal

\title{
Atmospheric Chemistry in Giant Planets, Brown Dwarfs, and Low-Mass Dwarf Stars II. Sulfur and Phosphorus
}

\author{
Channon Visscher, Katharina Lodders, and Bruce Fegley, Jr. \\ Planetary Chemistry Laboratory, Department of Earth \& Planetary Sciences, McDonnell \\ Center for the Space Sciences, Washington University, St. Louis, MO 63130-4899 \\ visscher@wustl.edu, lodders@wustl.edu, bfegley@wustl.edu
}

\begin{abstract}
Thermochemical equilibrium and kinetic calculations are used to model sulfur and phosphorus chemistry in giant planets, brown dwarfs, and extrasolar giant planets (EGPs). The chemical behavior of individual S- and P-bearing gases and condensates is determined as a function of pressure, temperature, and metallicity. The results are independent of particular model atmospheres and, in principle, the equilibrium composition along the pressure-temperature profile of any object can be determined. Hydrogen sulfide $\left(\mathrm{H}_{2} \mathrm{~S}\right)$ is the dominant S-bearing gas throughout substellar atmospheres and approximately represents the atmospheric sulfur inventory. Silicon sulfide ( $\mathrm{SiS}$ ) is a potential tracer of weather in substellar atmospheres. Disequilibrium abundances of phosphine $\left(\mathrm{PH}_{3}\right)$ approximately representative of the total atmospheric phosphorus inventory are expected to be mixed upward into the observable atmospheres of giant planets and $\mathrm{T}$ dwarfs. In hotter objects, several P-bearing gases (e.g., $\mathrm{P}_{2}, \mathrm{PH}_{3}, \mathrm{PH}_{2}, \mathrm{PH}, \mathrm{HCP}$ ) become increasingly important at high temperatures.
\end{abstract}

Subject headings: astrochemistry — planets and satellites: individual (Jupiter) — stars: low-mass, brown dwarfs — stars: individual (Gliese 229B, HD 209458)

\section{Introduction}

The relatively cool, dense atmospheres of substellar objects - gas giant planets, brown dwarfs, and extrasolar giant planets (EGPs) - are ideal environments for the formation of molecules and condensates and the establishment of equilibrium chemistry. For this reason, 
thermochemical models have been essential for interpreting and guiding spectroscopic observations of the atmospheres of giant planets (e.g., see Lewis 1969a,b; Barshay \& Lewis 1978; Fegley \& Lewis 1979; Fegley \& Prinn 1985, 1988; Fegley et al. 1991; Fegley \& Lodders 1994) and brown dwarfs (e.g., Fegley \& Lodders 1996). These models have also been useful for explaining how the optical and infrared spectra of substellar objects are influenced by CNO (Lodders \& Fegley 2002), alkali (Lodders 1999a), Ti and V (Lodders 2002), and condensation (e.g., Lodders \& Fegley 2006) chemistry.

After H, C, N, and O, sulfur and phosphorus are the next most abundant chemically reactive volatile elements in a solar system composition gas. Fegley \& Lodders (1994; hereafter FL94) modeled the chemistry of all naturally occurring elements, including S and P, along the atmospheric profiles of Jupiter and Saturn. Recently, Lodders \& Fegley (2002; hereafter LF02) modeled CNO chemistry in substellar objects as a function of pressure, temperature, and metallicity. Here we continue and extend these studies by employing thermochemical equilibrium and kinetic calculations to model sulfur and phosphorus chemistry in the atmospheres of substellar objects.

Our approach is similar to that of LF02. We compute the chemistry of S- and P-bearing gases and condensates as a function of total pressure, temperature, and metallicity, and our abundance results are independent of any particular atmospheric profile. In principle, the pressure-temperature profile for any substellar object may be superimposed on our abundance contour diagrams to find the equilibrium composition along the profile.

The paper is organized as follows. In section (§2) we describe our computational meth-

ods. In $\S 3$ we describe sulfur chemistry in a solar system composition gas: we identify major gases and condensates, and discuss the chemistry of individual S-bearing species as a function of total pressure, temperature, and metallicity. We then apply our results by examining the sulfur species along the atmospheric profiles of representative substellar objects. A similar treatment of phosphorus chemistry follows in $\S 4$. We discuss the relative roles of thermochemistry and photochemistry in $\S 5$, and conclude with a brief summary $(\S 6)$.

\section{Computational Methods}

Thermochemical equilibrium calculations were performed using a Gibbs free energy minimization code, previously used for modeling the atmospheric chemistry of Saturn (Visscher \& Fegley 2005). Where relevant, we considered the effects of vertical mixing on the abundances of gases (e.g., $\mathrm{PH}_{3}$ ) which serve as chemical probes of the deep atmospheres of Jupiter and Saturn. This was done using a chemical dynamical model described in Fegley 
\& Prinn (1985). We generally focus on temperatures of $1000 \mathrm{~K}$ and higher, where thermochemistry is expected to be much more important than photochemistry in the atmospheres of extrasolar giant planets close to their primary stars. Further discussion of thermochemical vs. photochemical processes is given in $§ 5$.

Thermodynamic data for the equilibrium calculations were taken from the compilations of Gurvich et al. (1989-1994), Robie \& Hemingway (1995), the fourth edition of the JANAF Tables (Chase 1999), and the thermodynamic database maintained in the Planetary Chemistry Laboratory (FL94; LF02). This database includes additional thermodynamic data from the literature for compounds absent from the other compilations, as well as several important data revisions for the sulfur and phosphorus species $\mathrm{SH}, \mathrm{S}_{2} \mathrm{O}, \mathrm{NS}, \mathrm{PS}, \mathrm{PH}, \mathrm{PH}_{3}$, $\mathrm{PN}$, and $\mathrm{Mg}_{3} \mathrm{P}_{2} \mathrm{O}_{8}(\mathrm{~s})$, which are incorrect in the JANAF tables (Lodders 1999b, 2004a). Thermodynamic data for $\mathrm{P}_{4} \mathrm{O}_{6}$ was taken from the JANAF tables for reasons cited in FL94.

All calculations were done with solar system (i.e., protosolar) elemental abundances from Lodders (2003). The effect of metallicity on sulfur and phosphorus chemistry was examined by running computations at $[\mathrm{M} / \mathrm{H}]=-0.5 \operatorname{dex}$ (subsolar), $[\mathrm{M} / \mathrm{H}]=0 \operatorname{dex}$ (solar), and $[\mathrm{M} / \mathrm{H}]$ $=+0.5$ dex (enhanced) metallicities, where $\mathrm{M}$ is any element of interest (e.g., $\mathrm{S}, \mathrm{P}, \mathrm{C}, \mathrm{O})^{1}$. The metallicity factor, $m$, is defined as $\log m=[\mathrm{M} / \mathrm{H}]$. Stellar abundance determinations show that element abundance ratios $[\mathrm{M} / \mathrm{H}]$ for elements of interest here vary similarly with $[\mathrm{Fe} / \mathrm{H}]$ between $-0.5 \leq[\mathrm{Fe} / \mathrm{H}] \leq+0.5$ dex (Edvardsson et al. 1993; Gustafsson et al. 1999; Chen et al. 2000; Smith et al. 2001; Ecuvillon et al. 2004; Huang et al. 2005), consistent with what one may expect from galactic chemical evolution models (e.g., Timmes et al. 1995). The slopes for fits of $[\mathrm{M} / \mathrm{H}]$ vs. $[\mathrm{Fe} / \mathrm{H}]$ are about $0.61,0.65$, and 0.6 for $\mathrm{M}=\mathrm{C}$, $\mathrm{S}$, and $\mathrm{O}$, respectively, which justifies our approach of "uniform" metallicity variations for these elements (e.g., $[\mathrm{S} / \mathrm{H}] \approx[\mathrm{P} / \mathrm{H}] \approx[\mathrm{C} / \mathrm{H}] \approx[\mathrm{O} / \mathrm{H}] \equiv[\mathrm{M} / \mathrm{H}]$ ) over the metallicity range considered here. Because phosphorus has weak lines, galactic chemical evolution models are used to estimate P abundances as a function of metallicity (e.g., Timmes et al. 1995; Samland 1998). We thus assume a similar enrichment in phosphorus as for other heavy elements. However, the effects of metallicity on chemical equilibrium abundances are explicitly treated below and can be used to study effects from non-uniform elemental abundance enrichments.

For each S- and P-bearing species, we discuss how the most plausible representative net thermochemical formation reaction depends on temperature, total pressure, and metallicity. For example, consider the formation of thioxophosphino (PS) via the net thermochemical reaction

$$
\mathrm{PH}_{3}+\mathrm{H}_{2} \mathrm{~S}=\mathrm{PS}+2.5 \mathrm{H}_{2}
$$

\footnotetext{
${ }^{1}$ We use the conventional notation $[\mathrm{M} / \mathrm{H}] \equiv \log (\mathrm{M} / \mathrm{H})-\log (\mathrm{M} / \mathrm{H})_{\text {solar }}$.
} 
This endothermic reaction proceeds toward the right with increasing temperature and the PS abundance increases. According to LeChâtelier's principle, this reaction also proceeds toward the right with decreasing pressure because there are 2 gas molecules on the left and 3.5 gas molecules on the right. Writing out the equilibrium constant $\left(K_{p}\right)$ expression for PS in terms of the total pressure $\left(P_{T}\right)$ and mole fractions ${ }^{2}$

$$
X_{\mathrm{PS}}=\left(X_{\mathrm{PH}_{3}} X_{\mathrm{H}_{2} \mathrm{~S}} / X_{\mathrm{H}_{2}}^{2.5}\right) K_{p} P_{T}^{-1.5}
$$

shows that the mole fraction of PS is proportional to $P_{T}^{-1.5}$. The metallicity dependence of $X_{\mathrm{PS}}$ enters only through the $\mathrm{PH}_{3}$ and $\mathrm{H}_{2} \mathrm{~S}$ abundances, whereas the $\mathrm{H}_{2}$ abundance is metallicity-independent by definition. Phosphine and $\mathrm{H}_{2} \mathrm{~S}$ are typically the most abundant P- and S-bearing gases, respectively. Hence $X_{\mathrm{PH}_{3}}$ and $X_{\mathrm{H}_{2} \mathrm{~S}}$ must each be expanded with a metallicity factor $m$, which results in an overall $m^{2}$ metallicity dependence for $X_{\mathrm{PS}}$, assuming $[\mathrm{S} / \mathrm{H}]=[\mathrm{P} / \mathrm{H}]$ (see above). This basic approach is used to describe the equilibrium chemical behavior of each S- and P-bearing species throughout the paper.

\section{Sulfur Chemistry}

\subsection{Sulfur Gas Chemistry}

The sulfur equilibrium gas chemistry as a function of temperature and total pressure in a protosolar composition gas is illustrated in Figure 1. The most abundant gases are $\mathrm{H}_{2} \mathrm{~S}$, $\mathrm{SH}$, or monatomic $\mathrm{S}$, and the $P-T$ regions where each gas is dominant are bounded by solid lines. Also shown are condensation curves (dotted lines) for S-bearing condensates (see §3.2) and the $\mathrm{H}_{2}=\mathrm{H}$ and $\mathrm{CH}_{4}=\mathrm{CO}$ equal abundance curves (dash-dot lines). Model atmosphere profiles for Jupiter $\left(T_{\text {eff }}=124 \mathrm{~K}, \log g=3.4\right)$, the $\mathrm{T}$ dwarf Gliese $229 \mathrm{~B}\left(T_{\text {eff }}=960 \mathrm{~K}\right.$, $\log g=5.0$; Marley et al. 1996), the close-orbiting EGP (or "Pegasi" planet) HD209458b $\left(T_{\text {eff }}=1350 \mathrm{~K}, \log g=3.0\right.$; Iro et al. 2005), an L dwarf $\left(T_{\text {eff }}=1800 \mathrm{~K}, \log g=5.0\right.$; Burrows et al. 2006), and an $\mathrm{M}$ dwarf $\left(T_{\text {eff }}=2600 \mathrm{~K}\right.$, dust-free, $\log g=5.0$; Tsuji et al. 1996) are indicated by dashed lines. The overall chemistry in the atmospheres of Jupiter and Gliese 229B differs slightly from the chemistry of a solar metallicity gas because Jupiter has a heavy element enrichment comparable to $[\mathrm{M} / \mathrm{H}] \approx+0.5$ dex (Lodders 1999a; LF02), whereas Gliese 229 B likely has a subsolar metallicity of $[\mathrm{M} / \mathrm{H}] \approx-0.3$ dex (Saumon et al. 2000); their P-T profiles are shown here for reference. However, as described below, the $P-T$ boundaries for the sulfur gases in Figure 1 are metallicity independent. This is because the $P-T$ boundaries

\footnotetext{
${ }^{2}$ The mole fraction abundance for a gas $i$ is defined as $X_{i}=\frac{\text { moles } i}{\text { total moles of all gases }}$.
} 
are defined by equal abundance ratios of the neighboring gases (e.g., $\mathrm{H}_{2} \mathrm{~S} / \mathrm{SH}, \mathrm{SH} / \mathrm{S}, \mathrm{H}_{2} \mathrm{~S} / \mathrm{S}$ ), so that the metallicity dependence cancels out.

Hydrogen sulfide $\left(\mathrm{H}_{2} \mathrm{~S}\right)$ is the dominant S-bearing gas in substellar atmospheres under most $P$ - $T$ conditions considered here. The absolute $\mathrm{H}_{2} \mathrm{~S}$ abundance is of course metallicity dependent (see §3.1.1). At high temperatures and low pressures, $\mathrm{H}_{2} \mathrm{~S}$ is replaced by $\mathrm{SH}$ via the net thermochemical reaction

$$
\mathrm{H}_{2} \mathrm{~S}=\mathrm{SH}+0.5 \mathrm{H}_{2},
$$

and $\mathrm{SH}$ becomes the dominant sulfur gas. The equilibrium constant expression for reaction (1) is

$$
K_{1}=\left(X_{\mathrm{SH}_{1}} X_{\mathrm{H}_{2}}^{0.5} / X_{\mathrm{H}_{2} \mathrm{~S}}\right) P_{T}^{0.5} .
$$

Rearranging and substituting for the temperature dependence of $K_{1}\left(\log K_{1}=3.37-8785 / T\right.$ from 800 to $2500 \mathrm{~K}$ ), the $\mathrm{H}_{2} \mathrm{~S} / \mathrm{SH}$ ratio is given by

$$
\log \left(X_{\mathrm{H}_{2} \mathrm{~S}} / X_{\mathrm{SH}}\right)=-3.37+8785 / T+0.5 \log P_{T}+0.5 \log X_{\mathrm{H}_{2}} .
$$

The $\mathrm{H}_{2} \mathrm{~S} / \mathrm{SH}$ ratio is independent of metallicity because the $m$ dependence of each S-bearing gas in reaction (1) cancels out and the $\mathrm{H}_{2}$ abundance is essentially constant $\left(X_{\mathrm{H}_{2}} \approx 0.84\right)$ over small metallicity variations. The solid line separating the $\mathrm{H}_{2} \mathrm{~S}$ and $\mathrm{SH}$ fields in Figure 1 shows where these two gases have equal abundances. With $X_{\mathrm{H}_{2} \mathrm{~S}} / X_{\mathrm{SH}}=1$ and $X_{\mathrm{H}_{2}} \approx 0.84$, equation (3) can be rewritten to give the $\mathrm{H}_{2} \mathrm{~S}=\mathrm{SH}$ equal abundance boundary:

$$
\log P_{T}=6.82-17570 / T,
$$

which is independent of metallicity. The abundance of each sulfur gas does not drop to zero as this line is crossed; $\mathrm{H}_{2} \mathrm{~S}$ is still present within the SH field and vice versa (see §3.1.2).

With increasing temperatures, $\mathrm{SH}$ dissociates and monatomic $\mathrm{S}$ becomes the dominant sulfur-bearing gas via

$$
\mathrm{SH}=\mathrm{S}+0.5 \mathrm{H}_{2}
$$

Using $\log K_{5}=2.36-7261 / T$ from 800 to $2500 \mathrm{~K}$ and rearranging, the $\mathrm{SH} / \mathrm{S}$ abundance ratio is given by

$$
\log \left(X_{\mathrm{SH}} / X_{\mathrm{S}}\right)=-2.36+7261 / T+0.5 \log P_{T}+0.5 \log X_{\mathrm{H}_{2}} .
$$

This ratio is also independent of metallicity because the $m$ dependence of each S-bearing gas in reaction (5) cancels out. With $X_{\mathrm{SH}} / X_{\mathrm{S}}=1$ and $X_{\mathrm{H}_{2}} \approx 0.84$, equation (6) is rewritten to give the position of the metallicity-independent $\mathrm{SH}=\mathrm{S}$ equal abundance line

$$
\log P_{T}=4.80-14522 / T \text {. }
$$


At the lowest total pressures considered here, monatomic $\mathrm{S}$ is the major sulfur gas (see Figure 1). At temperatures below $\sim 1509 \mathrm{~K}, \mathrm{H}_{2} \mathrm{~S}$ directly converts to monatomic $\mathrm{S}$ via the net thermochemical reaction

$$
\mathrm{H}_{2} \mathrm{~S}=\mathrm{S}+\mathrm{H}_{2} \text {. }
$$

The $\mathrm{H}_{2} \mathrm{~S} / \mathrm{S}$ abundance ratio follows from adding equations (3) and (6) as

$$
\log \left(X_{\mathrm{H}_{2} \mathrm{~S}} / X_{\mathrm{S}}\right)=-5.73+16046 / T+\log P_{T}+\log X_{\mathrm{H}_{2}},
$$

and is independent of metallicity. Again, with $X_{\mathrm{H}_{2} \mathrm{~S}} / X_{\mathrm{S}}=1$ and $X_{\mathrm{H}_{2}} \approx 0.84$, the metallicityindependent position of the $\mathrm{H}_{2} \mathrm{~S}=\mathrm{S}$ boundary is approximated by

$$
\log P_{T}=5.81-16046 / T \text {. }
$$

The $\mathrm{H}_{2} \mathrm{~S}=\mathrm{SH}, \mathrm{SH}=\mathrm{S}$, and $\mathrm{H}_{2} \mathrm{~S}=\mathrm{S}$ boundaries intersect at the $\mathrm{H}_{2} \mathrm{~S}-\mathrm{SH}-\mathrm{S}$ "triple point" at $T \sim 1509 \mathrm{~K}$ and $P_{T} \sim 10^{-4.82}$ bar, indicated by the triangle in Figure 1 and represented by the net thermochemical equilibrium

$$
\mathrm{H}_{2} \mathrm{~S}+\mathrm{S}=2 \mathrm{SH}
$$

The $P$ - T position of the triple point is independent of metallicity because the intersecting boundaries in equations (4), (7), and (10) are each independent of metallicity. At the triple point, all three gases have equal abundances $\mathrm{A}\left(\mathrm{H}_{2} \mathrm{~S}\right)=\mathrm{A}(\mathrm{SH})=\mathrm{A}(\mathrm{S}) \approx \frac{1}{3} \Sigma \mathrm{S}$ (where $\Sigma \mathrm{S}$ is the total elemental sulfur abundance) of one third of the total sulfur abundance.

As noted above, the $\mathrm{H}_{2}$ abundance is essentially constant $\left(X_{\mathrm{H}_{2}} \approx 0.84\right)$ over the small metallicity range considered here. However, at high $T$ and low $P_{T}, \mathrm{H}_{2}$ thermally dissociates to $\mathrm{H}$ via the net thermochemical reaction

$$
\mathrm{H}_{2}=2 \mathrm{H}
$$

The position of the $\mathrm{H}_{2}=\mathrm{H}$ equal abundance boundary is indicated by the dash-dot line in Figure 1. The abundance of $\mathrm{H}_{2}$ as a function of $P_{T}$ and $T$ in a solar system composition gas can be determined by solving the expression

$$
X_{\mathrm{H}_{2}} \approx \frac{1.9845+10^{u}-\sqrt{10^{u}\left(3.9690+10^{u}\right)}}{2.3670},
$$

where the variable $u$ is given by

$$
u=-23672 / T-\log P_{T}+6.2645 .
$$

At pressures and temperatures relevant for substellar atmospheres (Figure 1), 10 approaches zero and $X_{\mathrm{H}_{2}} \approx 0.84$. 


\subsubsection{Hydrogen Sulfide, $H_{2} S$ gas}

As shown in Figure 1, $\mathrm{H}_{2} \mathrm{~S}$ is expected to be the most abundant S-bearing gas throughout the atmospheres of substellar objects (e.g. FL94; Fegley \& Lodders 1996). Aside from minor amounts of sulfur $(\lesssim 9 \%)$ removed by metal sulfide clouds (see $\S 3.2), \mathrm{H}_{2} \mathrm{~S}$ approximately represents the atmospheric sulfur inventory until it is removed by very low temperature cloud formation and/or photochemical destruction. The $\mathrm{H}_{2} \mathrm{~S}$ abundance also slightly decreases at atmospheric levels below the Mg-silicate clouds where SiS gas is relatively abundant (see $\S 3.1 .4$ and $\S 3.3)$. Within the $\mathrm{H}_{2} \mathrm{~S}$ field and at the high temperatures below the metal sulfide clouds, the $\mathrm{H}_{2} \mathrm{~S}$ abundance is given by

$$
\log X_{\mathrm{H}_{2} \mathrm{~S}} \approx-4.52+[\mathrm{S} / \mathrm{H}]
$$

whereas above the metal sulfide clouds, the $\mathrm{H}_{2} \mathrm{~S}$ abundance is

$$
\log X_{\mathrm{H}_{2} \mathrm{~S}} \approx-4.56+[\mathrm{S} / \mathrm{H}]
$$

Figure 2a gives mole fraction contours (on a logarithmic scale) of $\mathrm{H}_{2} \mathrm{~S}$ as a function of temperature and total pressure in a solar metallicity gas. The $\mathrm{H}_{2} \mathrm{~S}$ abundance at higher or lower metallicities can be found by substituting for $[\mathrm{S} / \mathrm{H}]$ in equations (15) and (16). As discussed above, $\mathrm{H}_{2} \mathrm{~S}$ dissociates to $\mathrm{SH}$ and $\mathrm{S}$ at high temperatures. Inside the $\mathrm{SH}$ and $\mathrm{S}$ fields, the $\mathrm{H}_{2} \mathrm{~S}$ abundance remains proportional to $m$ and decreases when moving toward higher temperatures and lower total pressures.

\subsubsection{Mercapto, SH gas}

Mole fraction contours of $\mathrm{SH}$ as a function of $T$ and $P_{T}$ are shown in Figure $2 \mathrm{~b}$. Within the $\mathrm{H}_{2} \mathrm{~S}$ field $\left(X_{\mathrm{H}_{2} \mathrm{~S}} \approx X_{\Sigma \mathrm{S}}\right.$ and $\left.X_{\mathrm{H}_{2}} \approx 0.84\right)$, mercapto is governed by reaction (1). The $\mathrm{SH}$ abundance is given by substituting equation (15) into equation (3) and rearranging

$$
\log X_{\mathrm{SH}} \approx-1.11-8785 / T-0.5 \log P_{T}+[\mathrm{S} / \mathrm{H}]
$$

proportional to $P_{T}^{-0.5}$ and $m$. At high temperatures, $\mathrm{SH}$ is replaced by $\mathrm{S}$ via reaction (5). Within the $\mathrm{S}$ field, the $\mathrm{SH}$ abundance is proportional to $m$ and decreases when moving away from the SH-S boundary to higher $T$ and lower $P_{T}$.

\subsubsection{Monatomic Sulfur, S gas}

Mole fraction contours for monatomic $\mathrm{S}$ are shown in Figure 2c. Inside the $\mathrm{H}_{2} \mathrm{~S}$ field, monatomic sulfur gas is governed by reaction (8). The $\mathrm{S}$ abundance is given by rearranging 
equation (9), using $\log X_{\mathrm{H}_{2} \mathrm{~S}}$ from equation (15) and $\log X_{\mathrm{H}_{2}} \approx-0.08$ to give

$$
\log X_{\mathrm{S}} \approx 1.29-16046 / T-\log P_{T}+[\mathrm{S} / \mathrm{H}]
$$

proportional to $P_{T}^{-1}$ and $m$. As illustrated in Figure 1 , monatomic $\mathrm{S}$ is the dominant $\mathrm{S}$ bearing gas $\left(X_{\mathrm{S}} \approx X_{\Sigma \mathrm{S}}\right)$ at high $T$ and low $P_{T}$ in a solar composition gas. Thermal ionization of $\mathrm{S}$ only becomes important at temperatures higher than those shown in Figure 1, e.g., $\mathrm{S}^{+} / \mathrm{S} \sim 1$ at $6974 \mathrm{~K}\left(10^{-2}\right.$ bars $), 5340 \mathrm{~K}\left(10^{-4}\right.$ bars $)$, and $4326 \mathrm{~K}$ (10 ${ }^{-6}$ bars $)$.

\subsubsection{Silicon Sulfide, SiS gas}

The chemistry of SiS in a solar metallicity gas is shown in Figure 2d. Also shown are dashed lines for the condensation curves of forsterite $\left(\mathrm{Mg}_{2} \mathrm{SiO}_{4}\right)$ and enstatite $\left(\mathrm{MgSiO}_{3}\right)$. Condensation of Mg-silicates efficiently removes Si gases from the atmospheres of gas giant planets and cool brown dwarfs (Fegley \& Prinn 1988; FL94). The SiS abundance is controlled by the net thermochemical reaction

$$
\mathrm{SiO}+\mathrm{H}_{2} \mathrm{~S}=\mathrm{SiS}+\mathrm{H}_{2} \mathrm{O} .
$$

The SiS abundance at high temperatures below the Mg-silicate clouds is given by

$$
\log X_{\mathrm{SiS}} \approx-1.07+666 / T+[\mathrm{M} / \mathrm{H}]+\log X_{\mathrm{H}_{2} \mathrm{~S}},
$$

assuming $[\mathrm{O} / \mathrm{H}]=[\mathrm{S} / \mathrm{H}]($ see $\S 2)$. Below the clouds, $X_{\mathrm{SiS}}$ is relatively constant $(\sim 5 \mathrm{ppm}$ at $[\mathrm{M} / \mathrm{H}]=0)$ until $\mathrm{H}_{2} \mathrm{~S}$ is replaced by monatomic $\mathrm{S}$ at high $T$ and low $P_{T}$. The SiS abundance also decreases at $P_{T} \gtrsim 100$ bar as $\mathrm{CO}$ is replaced by $\mathrm{CH}_{4}$ (see Figure 1). This conversion increases the $\mathrm{H}_{2} \mathrm{O}$ abundance (see LF02), and drives reaction (19) toward the left to yield less $\mathrm{SiS}$.

At lower temperatures, above the clouds, the $\mathrm{SiO}$ abundance is governed by the reaction

$$
\mathrm{Mg}_{2} \mathrm{SiO}_{4}(\mathrm{~s})+\mathrm{SiO}+\mathrm{H}_{2} \mathrm{O}=2 \mathrm{MgSiO}_{3}(\mathrm{~s})+\mathrm{H}_{2} .
$$

Combined with reaction (19), the abundance of $\mathrm{SiS}$ is given by

$$
\log X_{\mathrm{SiS}} \approx 5.38-28151 / T-\log P_{T}-2 \log X_{\mathrm{H}_{2} \mathrm{O}}+[\mathrm{S} / \mathrm{H}] .
$$

Although reaction (19) does not indicate a dependence on $P_{T}$ and suggests a linear dependence on the $\mathrm{H}_{2} \mathrm{O}$ abundance, the $\mathrm{SiS}$ abundance in equation (22) is proportional to $P_{T}^{-1}$

and $X_{\mathrm{H}_{2} \mathrm{O}}^{-2}$. These dependencies enter through the $\mathrm{SiO}$ abundance governed by reaction (21). The $\mathrm{H}_{2} \mathrm{O}$ abundance above the $\mathrm{Mg}$-silicate clouds is approximated by

$$
\log X_{\mathrm{H}_{2} \mathrm{O}} \approx-3.58+0.46 /\left(1+10^{u}\right)+[\mathrm{O} / \mathrm{H}],
$$


where

$$
u=-11704 / T-2 \log P_{T}+9.78 .
$$

Substituting $\log X_{\mathrm{H}_{2} \mathrm{O}}$ from equation (23) into equation (22) shows that $X_{\mathrm{SiS}}$ is proportional to $m^{-1}$, assuming $[\mathrm{O} / \mathrm{H}]=[\mathrm{S} / \mathrm{H}]$ ( see $\S 2$ ). Curvature in the SiS abundance contours results from the dependence of the $\mathrm{H}_{2} \mathrm{O}$ abundance on the $\mathrm{CH}_{4} / \mathrm{CO}$ equilibrium (see LF02). For reference, $X_{\mathrm{H}_{2} \mathrm{O}} \approx 10^{-3.12}$ in $\mathrm{CH}_{4}$-dominated objects and $X_{\mathrm{H}_{2} \mathrm{O}} \approx 10^{-3.58}$ in CO-dominated objects with solar metallicity in atmospheric regions above the Mg-silicate clouds.

\subsection{Sulfur Condensation Chemistry}

With decreasing temperatures, sulfur condenses into $\mathrm{MnS}, \mathrm{Na}_{2} \mathrm{~S}, \mathrm{ZnS}$, and $\mathrm{NH}_{4} \mathrm{SH}$ cloud layers. Condensation affects the spectra of substellar objects by removing gases (and thus potential opacity sources) from the observable atmosphere, and by introducing cloud particles (Marley et al. 1996; Lodders 1999a; Burrows et al. 2000a; Lodders \& Fegley 2006).

The formation of a sulfur-bearing cloud requires that its constituent elements were not removed by condensation into more refractory cloud layers at deeper levels. For example, one might naively expect $\mathrm{FeS}$ cloud formation because $\mathrm{FeS}$ is a well-known condensate in the equilibrium condensation sequence of the solar nebula gas. However, condensation of $\mathrm{FeS}$ is preceded by Fe metal condensation and in the high-gravity environment of substellar objects, iron settles into a deep cloud layer at high temperatures (e.g. Prinn \& Olaguer 1981; FL94; Lodders 1999a; LF02; Lodders \& Fegley 2006). Hence no Fe metal is left at lower temperatures when FeS could condense. Note that if $\mathrm{FeS}$ condensation did occur, all $\mathrm{H}_{2} \mathrm{~S}$ would be removed because $\mathrm{Fe} / \mathrm{S} \approx 1.9$. However, the measured $\mathrm{H}_{2} \mathrm{~S}$ abundance of $\sim 2.4$ times the protosolar $\mathrm{H}_{2} \mathrm{~S} / \mathrm{H}_{2}$ ratio in Jupiter's atmosphere (Niemann et al. 1998; Wong et al. 2004) requires Fe metal cloud formation at deep atmospheric levels.

Sulfur thus condenses as other sulfides with metals ( $\mathrm{Mn}, \mathrm{Na}, \mathrm{Zn}$ ) that are not already removed into high-temperature condensates. The abundances of $\mathrm{Mn}, \mathrm{Zn}$, and $\mathrm{Na}$ are all lower than that of $\mathrm{S}$ and condensation of these sulfides only depletes the atmosphere of $\sim 9 \%$ of its entire sulfur inventory. Therefore, $\mathrm{H}_{2} \mathrm{~S}$ gas remains in $\mathrm{T}$ dwarfs, $\mathrm{L}$ dwarfs, and Pegasi planets, and is only depleted in objects with low enough temperatures for $\mathrm{NH}_{4} \mathrm{SH}$ condensation. Table 1 lists the calculated condensation temperatures of $\mathrm{MnS}, \mathrm{Na}_{2} \mathrm{~S}, \mathrm{ZnS}$, and $\mathrm{NH}_{4} \mathrm{SH}$ for HD209458b and a model $\mathrm{L}$ dwarf with $[\mathrm{M} / \mathrm{H}] \approx 0$, for Jupiter $([\mathrm{M} / \mathrm{H}] \approx$ $+0.5)$, and for Gliese $229 \mathrm{~B}([\mathrm{M} / \mathrm{H}] \approx-0.3)$, assuming uniform enrichments and/or depletions of heavy element abundances. 


\subsubsection{Alabandite, $M n S$, condensation}

The most refractory S-bearing condensate in substellar atmospheres is MnS (Figure 1). Alabandite clouds form via the net thermochemical reaction

$$
\mathrm{Mn}+\mathrm{H}_{2} \mathrm{~S}=\mathrm{MnS}(\mathrm{s})+\mathrm{H}_{2},
$$

where the condensation temperature is approximated by

$$
\begin{aligned}
10^{4} / T_{\text {cond }}(\mathrm{MnS}) & \approx 7.45-0.42\left(\log P_{T}+[\mathrm{Mn} / \mathrm{H}]+[\mathrm{S} / \mathrm{H}]\right) \\
& \approx 7.45-0.42 \log P_{T}-0.84[\mathrm{M} / \mathrm{H}],
\end{aligned}
$$

assuming $[\mathrm{Mn} / \mathrm{H}]=[\mathrm{S} / \mathrm{H}]$ (see $\S 2$ ). Because MnS condenses at sufficiently high temperatures (e.g. $\sim 1340 \mathrm{~K}$ at 1 bar), MnS clouds are expected in most substellar atmospheres. The Mn abundance is $2 \%$ that of sulfur and thus MnS cloud formation removes all Mn and $2 \%$ of all sulfur from the atmosphere.

\subsubsection{Sodium Sulfide, $\mathrm{Na}_{2} \mathrm{~S}$, condensation}

The $\mathrm{Na}_{2} \mathrm{~S}$ cloud layer forms via the net thermochemical reaction

$$
2 \mathrm{Na}+\mathrm{H}_{2} \mathrm{~S}=\mathrm{Na}_{2} \mathrm{~S}(\mathrm{~s})+\mathrm{H}_{2},
$$

The condensation temperature of $\mathrm{Na}_{2} \mathrm{~S}$ as a function of $P_{T}$ and metallicity is approximated by

$$
\begin{aligned}
10^{4} / T_{\text {cond }}\left(\mathrm{Na}_{2} \mathrm{~S}\right) & \approx 10.05-0.72\left(\log P_{T}+[\mathrm{Na} / \mathrm{H}]+0.5[\mathrm{~S} / \mathrm{H}]\right) \\
& \approx 10.05-0.72 \log P_{T}-1.08[\mathrm{M} / \mathrm{H}]
\end{aligned}
$$

assuming $[\mathrm{Na} / \mathrm{H}]=[\mathrm{S} / \mathrm{H}]($ see $\S 2)$, and is shown in Figure 1 for a solar-metallicity gas. Below the $\mathrm{Na}_{2} \mathrm{~S}$ cloud, monatomic $\mathrm{Na}$ is the most abundant Na-bearing gas, followed closely by $\mathrm{NaCl}$. With decreasing temperatures, $\mathrm{NaCl}$ becomes increasingly important, but its abundance never exceeds that of monatomic Na below the cloud (Lodders 1999a). Sodium sulfide condensation effectively removes all sodium and $\sim 6.5 \%$ of all sulfur from the atmosphere because the protosolar $\mathrm{Na}$ abundance is $13 \%$ of the protosolar $\mathrm{S}$ abundance.

\subsubsection{Sphalerite, $Z n S$, condensation}

Sphalerite clouds form by the net thermochemical reaction

$$
\mathrm{Zn}+\mathrm{H}_{2} \mathrm{~S}=\mathrm{ZnS}(\mathrm{s})+\mathrm{H}_{2} .
$$


The condensation temperature of $\mathrm{ZnS}$ as a function of $P_{T}$ and metallicity is given by

$$
\begin{aligned}
10^{4} / T_{\text {cond }}(\mathrm{ZnS}) & \approx 12.52-0.63\left(\log P_{T}+[\mathrm{Zn} / \mathrm{H}]+[\mathrm{S} / \mathrm{H}]\right) \\
& \approx 12.52-0.63 \log P_{T}-1.26[\mathrm{M} / \mathrm{H}]
\end{aligned}
$$

assuming $[\mathrm{Zn} / \mathrm{H}]=[\mathrm{S} / \mathrm{H}]$ ( see $\S 2$ ). Sphalerite cloud formation effectively removes all $\mathrm{Zn}$ and $\sim 0.3 \%$ of $\mathrm{H}_{2} \mathrm{~S}$ from the atmosphere.

\subsubsection{Ammonium Hydrogen Sulfide, $\mathrm{NH}_{4} \mathrm{SH}$, condensation}

Sulfur condenses as $\mathrm{NH}_{4} \mathrm{SH}$ via the net thermochemical reaction

$$
\mathrm{NH}_{3}+\mathrm{H}_{2} \mathrm{~S}=\mathrm{NH}_{4} \mathrm{SH}(\mathrm{s})
$$

in the cool upper atmospheres of giant planets (Figure 1), where $\mathrm{H}_{2} \mathrm{~S}$ and $\mathrm{NH}_{3}$ are the major $\mathrm{S}$ - and N-bearing gases, respectively. The $\mathrm{NH}_{4} \mathrm{SH}$ condensation temperature as a function of $P_{T}$ and metallicity is approximated by

$$
\begin{aligned}
10^{4} / T_{\text {cond }}\left(\mathrm{NH}_{4} \mathrm{SH}\right) & \approx 48.91-4.15\left(\log P_{T}+0.5[\mathrm{~N} / \mathrm{H}]+0.5[\mathrm{~S} / \mathrm{H}]\right) \\
& \approx 48.91-4.15 \log P_{T}-4.15[\mathrm{M} / \mathrm{H}]
\end{aligned}
$$

assuming $[\mathrm{N} / \mathrm{H}]=[\mathrm{S} / \mathrm{H}]$ (see $\S 2)$. This expression differs slightly from LF02 due to the revised solar elemental abundances of Lodders (2003). The formation of a $\mathrm{NH}_{4} \mathrm{SH}$ cloud is expected to efficiently remove all sulfur from the atmosphere because $\mathrm{NH}_{3}$ is $\sim 4.4$ times more abundant than $\mathrm{H}_{2} \mathrm{~S}$ in a protosolar composition gas.

\subsubsection{Hydrogen Sulfide, $H_{2} S$, condensation}

Hydrogen sulfide cloud formation is only possible in cool objects (such as Uranus and Neptune) if $\mathrm{NH}_{3}$ is absent or less abundant than $\mathrm{H}_{2} \mathrm{~S}$, since ammonia will consume atmospheric sulfur to form $\mathrm{NH}_{4} \mathrm{SH}$ via reaction (31) (e.g., see Fegley et al. 1991). At sufficiently low temperatures, $\mathrm{H}_{2} \mathrm{~S}$ condensation may occur via the net reaction

$$
\mathrm{H}_{2} \mathrm{~S}=\mathrm{H}_{2} \mathrm{~S}(\mathrm{~s}) \text {. }
$$

The $\mathrm{H}_{2} \mathrm{~S}$ condensation temperature is approximated by

$$
10^{4} / T_{\text {cond }}\left(\mathrm{H}_{2} \mathrm{~S}\right) \approx 86.49-8.54 \log P_{T}-8.54[\mathrm{~S} / \mathrm{H}]
$$

We found that no other S-bearing condensates are stable (OCS, $\mathrm{SO}_{2}$, elemental $\left.\mathrm{S}\right)$ over this $P$ - $T$ range in a protosolar composition gas. 


\subsection{Sulfur Chemistry in Substellar Objects}

Figures 3a-3d summarize the equilibrium sulfur gas chemistry computed along the $P-T$ profiles of four representative substellar objects: Jupiter $\left(T_{\text {eff }}=124 \mathrm{~K}\right)$, the $\mathrm{T}$ dwarf Gliese $229 \mathrm{~B}\left(T_{\text {eff }}=960 \mathrm{~K}\right)$, the Pegasi planet HD209458b $\left(T_{\text {eff }}=1350 \mathrm{~K}\right)$, and an $\mathrm{L}$ dwarf $\left(T_{\text {eff }}=\right.$ $1800 \mathrm{~K}$ ) (see $\S 3.1$ ). The profiles for Jupiter and Gliese $229 \mathrm{~B}$ were computed at $[\mathrm{M} / \mathrm{H}] \approx+0.5$ and $[\mathrm{M} / \mathrm{H}] \approx-0.3$, respectively, assuming uniform enrichments and depletions in elemental abundances. The upper atmosphere of HD209458b is heated by a large incoming stellar flux, which is responsible for the shape of this planet's $P$ - $T$ profile (Figure 1 ) and hence the curvature in all gas abundances near $1800 \mathrm{~K}$. Also shown are gases which are strongly affected by S-bearing cloud formation (e.g., $\mathrm{Na}, \mathrm{NaCl}, \mathrm{Mn}, \mathrm{Zn}$ ). The condensation temperatures of $\mathrm{Mg}_{2} \mathrm{SiO}_{4}$ (Fo), $\mathrm{MgSiO}_{3}$ (En), MnS, $\mathrm{Na}_{2} \mathrm{~S}$, and $\mathrm{ZnS}$ are indicated by arrows (see Table 1). The Jupiter profile intersects the forsterite condensation curve at high temperatures outside the range of Figure 3a. The Gliese 229B profile intersects the $\mathrm{ZnS}$ condensation curve at 780 $\mathrm{K}$, outside the range of Figure 3b. In contrast, $\mathrm{ZnS}$ does not condense in the atmospheres of HD209458b or the L dwarf.

Hydrogen sulfide is the most abundant S-bearing gas throughout the atmospheres of substellar objects $\left(X_{\mathrm{H}_{2} \mathrm{~S}} \approx X_{\Sigma \mathrm{S}}\right)$. The $\mathrm{H}_{2} \mathrm{~S}$ abundance slightly increases when silicon in SiS is removed by Mg-silicate cloud formation (e.g., see Figures 3b-3d), and slightly decreases when sulfur is removed by metal sulfide cloud formation (e.g., see Figure 3a).

The Galileo entry probe measured $\mathrm{H}_{2} \mathrm{~S}$ down to the $\sim 20$ bar level on Jupiter (Niemann et al. 1998; Wong et al. 2004), where the observed $\mathrm{H}_{2} \mathrm{~S}$ abundance of 2.4 times the solar $\mathrm{H}_{2} \mathrm{~S} / \mathrm{H}_{2}$ ratio should represent the total sulfur inventory in Jupiter's atmosphere (e.g., Barshay \& Lewis 1978; FL94; Lodders 2004b). Ground-based observations have failed to detect $\mathrm{H}_{2} \mathrm{~S}$ on Jupiter and Saturn because of its removal by condensation, its short photochemical lifetime, and the lack of major $\mathrm{H}_{2} \mathrm{~S}$ features in the $5 \mu \mathrm{m}$ window. Observations of Jupiter at $2.7 \mu \mathrm{m}$ by KAO (Larson et al. 1984) and at $8.5 \mu \mathrm{m}$ by Voyager (Bézard et al. 1983) provide only upper limits because these wavelengths probe atmospheric levels where $\mathrm{H}_{2} \mathrm{~S}$ is depleted by $\mathrm{NH}_{4} \mathrm{SH}$ condensation. The HST detection of $\mathrm{H}_{2} \mathrm{~S}$ in the Shoemaker-Levy 9 impact region suggested excavation of Jovian atmosphere from regions below the $\mathrm{NH}_{4} \mathrm{SH}$ cloud where $\mathrm{H}_{2} \mathrm{~S}$ is more abundant (Noll et al. 1995; Zahnle et al. 1995).

Based on tropospheric $\mathrm{NH}_{3}$ and $\mathrm{H}_{2} \mathrm{~S}$ abundances, $\mathrm{NH}_{4} \mathrm{SH}$ cloud formation is expected to occur near the $220 \mathrm{~K}, 2.4$ bar level on Jupiter (cf. FL94). This should efficiently remove $\mathrm{H}_{2} \mathrm{~S}$ from the gas because $\mathrm{NH}_{3} / \mathrm{H}_{2} \mathrm{~S} \sim 7.5 \pm 3.4$ in Jupiter's atmosphere (Wong et al. 2004). The inferred $\mathrm{NH}_{4} \mathrm{SH}$ cloud layer detected by the Galileo entry probe nephelometer was thin and tenuous, presumably due to the probe's entry in a relatively clear $5 \mu \mathrm{m}$ hot spot (West et al. 2004). 
In contrast, $\mathrm{NH}_{4} \mathrm{SH}$ cloud formation is not expected in the warmer atmospheres of brown dwarfs or Pegasi planets because their $P-T$ profiles do not intersect the $\mathrm{NH}_{4} \mathrm{SH}$ condensation curve (see Figure 1), and $\mathrm{H}_{2} \mathrm{~S}$ gas remains. Measurements of $\mathrm{H}_{2} \mathrm{~S}$ in these objects should therefore approximately represent their bulk atmospheric sulfur inventory (e.g. Fegley \& Lodders 1996). Saumon et al. (2000) investigated the observability of $\mathrm{H}_{2} \mathrm{~S}$ and found that a $\mathrm{H}_{2} \mathrm{~S}$ feature at $2.1 \mu \mathrm{m}$ is potentially detectable in the infrared spectrum of Gliese 229B. In the uppermost atmospheres of brown dwarfs and Pegasi planets, $\mathrm{H}_{2} \mathrm{~S}$ is plausibly destroyed by photochemistry (see §5), as is expected for Jupiter (e.g., Prinn \& Owen 1976).

Over the $P-T$ range considered here, the next most abundant S-bearing gases after $\mathrm{H}_{2} \mathrm{~S}$ are $\mathrm{SH}$ (at low temperatures) or $\mathrm{SiS}$ (at high temperatures). The mercapto radical is generally the second or third most abundant sulfur gas throughout substellar atmospheres. Yamamura et al. (2000) identified SH at $\sim 3.67 \mu \mathrm{m}$ in the published infrared spectrum of $\mathrm{R}$ Andromedae, a S-type star. Their inferred $\mathrm{SH} / \mathrm{H}$ ratio of $\sim 10^{-7}$ is consistent with thermochemical equilibrium (Tsuji 1973, and Figure 2b). Berdyugina \& Livingston (2002) identified SH at $\sim 3280 \AA$ in the Sun's photosphere. They do not give column densities, but computed synthetic spectra at 5250 and $4750 \mathrm{~K}$. We calculated SH mole fractions of $\sim 9 \times 10^{-9}(5250 \mathrm{~K})$ and $\sim 5 \times 10^{-9}(4750 \mathrm{~K})$ using the solar model atmosphere of Edvardsson et al. (1993). Using the effective temperatures for reference, we also compute SH column densities of $\sim 7 \times 10^{12}(960 \mathrm{~K}), \sim 2 \times 10^{17}(1350 \mathrm{~K})$, and $\sim 2 \times 10^{17} \mathrm{~cm}^{-2}(1800 \mathrm{~K})$ on Gliese 229B, HD209458b, and the L dwarf, respectively, versus the SH column density of $\sim 4 \times 10^{20}$ $\mathrm{cm}^{-2}$ in R Andromedae (Yamamura et al. 2000). The equilibrium SH abundances expected for brown dwarfs and Pegasi planets may be too low for reliable quantitative analysis.

The relative importance of $\mathrm{SiS}$ increases with increasing temperature, and peak SiS abundances of $\sim 6 \mathrm{ppm}$ at $[\mathrm{M} / \mathrm{H}]=0$ and $\sim 60 \mathrm{ppm}$ at $[\mathrm{M} / \mathrm{H}]=+0.5$ are achieved at $P-T$ conditions close to the condensation temperatures of the Mg-silicate clouds. With their condensation, silicon is removed from the atmosphere and the abundance of SiS and other Si-bearing gases drop. This makes SiS a potential tracer of weather in Pegasi planets and L dwarfs, analogous to FeH in T dwarfs (Burgasser et al. 2002), and gaps in the Mg-silicate cloud layers may expose regions where SiS is relatively abundant. In cooler objects, the SiS fundamental absorption band near $13.3 \mu \mathrm{m}$ may be difficult to distinguish from ammonia features as $\mathrm{NH}_{3}$ replaces $\mathrm{N}_{2}$ to become the dominant N-bearing gas; the first SiS overtone at $6.6 \mu \mathrm{m}$ has been observed in the carbon giant WZ Cas (Aoki et al. 1998), though this feature will likely be overwhelmed by $\mathrm{H}_{2} \mathrm{O}$ absorption in substellar atmospheres.

The increasing importance of $\mathrm{NaCl}$ instead of $\mathrm{Na}$ and the removal of $\mathrm{Na}$ by $\mathrm{Na}_{2} \mathrm{~S}$ cloud formation is a plausible cause of the observed weakening of $\mathrm{Na}$ atomic lines throughout the $\mathrm{L}$ dwarf spectral sequence and their disappearance in early $\mathrm{T}$ dwarfs (e.g. Kirkpatrick et 
al. 1999; McLean et al. 2003); this is further enhanced by pressure broadening of the $\mathrm{Na}$ I doublet (e.g. Tsuji et al. 1996; Burrows et al. 2000b; Liebert et al. 2000). Sodium sulfide is expected to condense at the $\sim 1370 \mathrm{~K}$ level in Jupiter's atmosphere and the $\sim 1000 \mathrm{~K}$ level in Gliese 229B (see Table 1). The L dwarf and the Pegasi planet HD209458b are too warm for $\mathrm{Na}_{2} \mathrm{~S}$ condensation (assuming $[\mathrm{M} / \mathrm{H}] \approx 0$; see Figure 1 ) and $\mathrm{Na}$ remains in the gas. This is consistent with the detection of $\mathrm{Na}$ in the atmosphere of HD209458b (Charbonneau et al. 2002), though the chemistry results of Lodders (1999a) suggest that limited $\mathrm{Na}_{2} \mathrm{~S}$ cloud formation may occur on this planet if night-side temperatures are low enough (e.g., Fortney et al. 2003, 2005; Iro et al. 2005; Barman et al. 2005), or if its metallicity is sufficiently enhanced. However, while $\mathrm{Na}$ chemistry is strongly affected by $\mathrm{Na}_{2} \mathrm{~S}$ condensation, $\mathrm{S}$ chemistry remains almost unchanged because $\mathrm{Na}_{2} \mathrm{~S}$ cloud formation only removes $6 \%$ of all sulfur (see $\S 3.2 .2$ ).

The formation of the MnS cloud layer effectively removes Mn from the atmospheres of substellar objects. Similarly, ZnS condensation removes Zn from the atmosphere of Jupiter $([\mathrm{M} / \mathrm{H}] \approx+0.5)$ and Gliese $229 \mathrm{~B}([\mathrm{M} / \mathrm{H}] \approx-0.3)$ above the $\sim 980 \mathrm{~K}$ and $\sim 780 \mathrm{~K}$ levels, respectively. In contrast, the atmospheres of $\mathrm{L}$ dwarfs and Pegasi planets are too warm for $\mathrm{ZnS}$ condensation and $\mathrm{Zn}$ will remain in the gas.

\section{Phosphorus Chemistry}

\subsection{Phosphorus Gas Chemistry}

The phosphorus equilibrium gas chemistry as a function of temperature and total pressure in a protosolar composition gas is illustrated in Figure 4. The $P$ - $T$ regions indicating the most abundant phosphorus bearing gas are bounded by solid lines. Also shown is the condensation curve for $\mathrm{NH}_{4} \mathrm{H}_{2} \mathrm{PO}_{4}$ (dotted line), model atmosphere profiles for representative substellar objects (dashed lines; see §3.1), and the $\mathrm{H}_{2}=\mathrm{H}$ and $\mathrm{CH}_{4}=\mathrm{CO}$ equal abundance curves (dash-dot lines). Phosphorus chemistry is considerably more complex than that for $\mathrm{C}, \mathrm{N}, \mathrm{O}$, and $\mathrm{S}$, and several P-bearing species become abundant at elevated temperatures (Barshay \& Lewis 1978; Fegley \& Lewis 1980; FL94).

Under equilibrium conditions, $\mathrm{P}_{4} \mathrm{O}_{6}$ is the dominant phosphorus gas at low temperatures, and is replaced by $\mathrm{PH}_{3}$ or $\mathrm{P}_{2}$ as temperatures increase. The conversion of $\mathrm{P}_{4} \mathrm{O}_{6}$ to $\mathrm{PH}_{3}$ occurs by net thermochemical reaction:

$$
\mathrm{P}_{4} \mathrm{O}_{6}+12 \mathrm{H}_{2}=4 \mathrm{PH}_{3}+6 \mathrm{H}_{2} \mathrm{O} \text {. }
$$

In $\mathrm{CH}_{4}$-dominated objects, the $\mathrm{PH}_{3}=\mathrm{P}_{4} \mathrm{O}_{6}$ equal abundance boundary is approximated by

$$
\log P_{T} \approx-11.40+12360 / T+2[\mathrm{O} / \mathrm{H}]+[\mathrm{P} / \mathrm{H}]
$$




$$
\approx-11.40+12360 / T+3[\mathrm{M} / \mathrm{H}]
$$

assuming $[\mathrm{O} / \mathrm{H}] \approx[\mathrm{P} / \mathrm{H}]$ (see $\S 2)$. The net reaction of $\mathrm{P}_{4} \mathrm{O}_{6}$ to $\mathrm{P}_{2}$ occurs at lower $P_{T}$ in CO-dominated objects:

$$
\mathrm{P}_{4} \mathrm{O}_{6}+6 \mathrm{H}_{2}=2 \mathrm{P}_{2}+6 \mathrm{H}_{2} \mathrm{O}
$$

and the position of the $\mathrm{P}_{2}=\mathrm{P}_{4} \mathrm{O}_{6}$ equal abundance boundary is approximated by

$$
\begin{aligned}
\log P_{T} & \approx 45.17-51048 / T-6[\mathrm{O} / \mathrm{H}]-[\mathrm{P} / \mathrm{H}] \\
& \approx 45.17-51048 / T-7[\mathrm{M} / \mathrm{H}]
\end{aligned}
$$

assuming $[\mathrm{O} / \mathrm{H}] \approx[\mathrm{P} / \mathrm{H}]$ (see $\S 2)$. The relative importance of reactions (35) and (37) depends on the position of an object's $P$ - $T$ profile relative to the $\mathrm{PH}_{3}-\mathrm{P}_{4} \mathrm{O}_{6}-\mathrm{P}_{2}$ triple point at $T \sim$ $1101 \mathrm{~K}$ and $P_{T} \sim 10^{-1.20}$ bar, where all three gases have equal abundances $\left[\mathrm{A}\left(\mathrm{PH}_{3}\right)=\right.$ $\left.\mathrm{A}\left(\mathrm{P}_{4} \mathrm{O}_{6}\right)=\mathrm{A}\left(\mathrm{P}_{2}\right) \approx \frac{1}{7} \Sigma \mathrm{P}\right]$. The positions of all the triple points shown in Figure 4 are listed in Table 2.

In $\mathrm{L}$ dwarf atmospheres, $\mathrm{PH}_{3}$ and $\mathrm{P}_{2}$ have similar abundances and are converted into each other by the net thermochemical reaction

$$
2 \mathrm{PH}_{3}=\mathrm{P}_{2}+3 \mathrm{H}_{2}
$$

The $\mathrm{PH}_{3}=\mathrm{P}_{2}$ equal abundance boundary in a solar metallicity gas is approximated by

$$
\log P_{T} \approx-1.56 \times 10^{7} / T^{2}+2.13 \times 10^{4} / T-7.68
$$

from 1101 to $1330 \mathrm{~K}$, and shifts to higher $P_{T}$ and lower $T$ with increasing metallicity. At deeper atmospheric levels, $\mathrm{PH}_{2}$ becomes the most abundant phosphorus gas. In $\mathrm{T}$ dwarfs and cool $\mathrm{L}$ dwarfs $\mathrm{PH}_{2}$ replaces $\mathrm{PH}_{3}$ via

$$
\mathrm{PH}_{3}=\mathrm{PH}_{2}+0.5 \mathrm{H}_{2}
$$

The $\mathrm{PH}_{3}=\mathrm{PH}_{2}$ boundary is given by

$$
\log P_{T} \approx 7.71-10888 / T
$$

and is independent of metallicity because the $m$ dependence for each P-bearing gas in reaction (41) cancels and the $\mathrm{H}_{2}$ abundance is essentially constant over small metallicity variations.

In Pegasi planets and hot $\mathrm{L}$ dwarfs, $\mathrm{PH}_{2}$ replaces $\mathrm{P}_{2}$ via

$$
\mathrm{P}_{2}+2 \mathrm{H}_{2}=2 \mathrm{PH}_{2}
$$


The position of the $\mathrm{P}_{2}=\mathrm{PH}_{2}$ boundary in a solar metallicity gas is approximated by

$$
\log P_{T} \approx-1.68 \times 10^{7} / T^{2}+2.62 \times 10^{4} / T-10.68 .
$$

from 1330 to $1780 \mathrm{~K}$, and shifts to higher $P_{T}$ and $T$ with increasing metallicity. The $\mathrm{PH}_{3}=\mathrm{P}_{2}$, $\mathrm{PH}_{3}=\mathrm{PH}_{2}$, and $\mathrm{P}_{2}=\mathrm{PH}_{2}$ boundaries intersect at $T \sim 1330 \mathrm{~K}$ and $P_{T} \sim 10^{-0.48}$ bar, where all three gases have equal abundances $\left[\mathrm{A}\left(\mathrm{PH}_{3}\right)=\mathrm{A}\left(\mathrm{PH}_{2}\right)=\mathrm{A}\left(\mathrm{P}_{2}\right) \approx \frac{1}{4} \Sigma \mathrm{P}\right]$.

At even higher temperatures, $\mathrm{PH}_{2}$ thermally dissociates via

$$
\mathrm{PH}_{2}=\mathrm{P}+\mathrm{H}_{2},
$$

and monatomic $\mathrm{P}$ becomes the major $\mathrm{P}$-bearing gas. The position of the $\mathrm{PH}_{2}=\mathrm{P}$ boundary given by

$$
\log P_{T} \approx 5.00-11233 / T,
$$

is independent of metallicity because the $m$ dependence for each P-bearing gas cancels out in reaction (45). As for sulfur, thermal ionization of $\mathrm{P}$ only becomes important at temperatures higher than those shown in Figure 4, e.g., $\mathrm{P}^{+} / \mathrm{P} \sim 1$ at $6088 \mathrm{~K}\left(10^{-2}\right.$ bars $), 4836 \mathrm{~K}\left(10^{-4}\right.$ bars), and $4054 \mathrm{~K}\left(10^{-6}\right.$ bars $)$.

\subsubsection{Tetraphosphorus Hexaoxide, $P_{4} O_{6}$ gas}

The equilibrium abundances of $\mathrm{P}_{4} \mathrm{O}_{6}$ as a function of $T$ and $P_{T}$ for solar metallicity are illustrated in Figure 5a. At high temperatures $(\gtrsim 1000 \mathrm{~K})$, the $\mathrm{P}_{4} \mathrm{O}_{6}$ abundances depend on which P-bearing gas is dominant. For example, within the $\mathrm{PH}_{3}$ field, the $\mathrm{P}_{4} \mathrm{O}_{6}$ abundance is controlled by reaction (35) and is proportional to $P_{T}^{-3}$ and $m^{10}$, assuming $[\mathrm{O} / \mathrm{H}] \approx[\mathrm{P} / \mathrm{H}]$ (see $\S 2$ ). Inside the $\mathrm{P}_{2}$ field, the $\mathrm{P}_{4} \mathrm{O}_{6}$ abundance is controlled by reaction (37) and is proportional to $P_{T}$ and $m^{8}$, assuming $[\mathrm{O} / \mathrm{H}] \approx[\mathrm{P} / \mathrm{H}]$ (see $\S 2$ ). In both cases, the $\mathrm{P}_{4} \mathrm{O}_{6}$ abundance rapidly decreases with temperature and is strongly dependent on metallicity.

At low temperatures $(\lesssim 1000 \mathrm{~K}), \mathrm{P}_{4} \mathrm{O}_{6}$ is the dominant P-bearing gas at equilibrium (Figure 4), and its abundance is proportional to $m$, assuming $[\mathrm{O} / \mathrm{H}] \approx[\mathrm{P} / \mathrm{H}]$ (see $\S 2$ ). The maximum $\mathrm{P}_{4} \mathrm{O}_{6}$ abundance is $X_{\mathrm{P}_{4} \mathrm{O}_{6}} \approx \frac{1}{4} X_{\Sigma \mathrm{P}}$ because each molecule of $\mathrm{P}_{4} \mathrm{O}_{6}$ contains four phosphorus atoms. However, completely insignificant amounts of $\mathrm{P}_{4} \mathrm{O}_{6}$ are expected in the upper atmospheres of giant planets and $\mathrm{T}$ dwarfs because the $\mathrm{PH}_{3}$ to $\mathrm{P}_{4} \mathrm{O}_{6}$ conversion is kinetically inhibited inside the $\mathrm{PH}_{3}$ stability field where essentially no $\mathrm{P}_{4} \mathrm{O}_{6}$ exists (see §4.3). 


\subsubsection{Phosphine, $\mathrm{PH}_{3}$ gas}

Chemical equilibrium abundances of $\mathrm{PH}_{3}$ are shown in Figure $5 \mathrm{~b}$ as a function of $T$ and $P_{T}$. At high temperatures $(T \gtrsim 1000 \mathrm{~K}), \mathrm{PH}_{3}$ abundances generally increase with $P_{T}$ but decrease with $T$ when other P-bearing gases are dominant. For example, within the $\mathrm{P}_{2}$ field the $\mathrm{PH}_{3}$ abundance is governed by reaction (39) and is approximated by

$$
\log X_{\mathrm{PH}_{3}} \approx-9.03+3737 / T+\log P_{T}+0.5[\mathrm{P} / \mathrm{H}],
$$

proportional to $P_{T}$ and $m^{0.5}$. At higher total pressures, $\mathrm{PH}_{3}$ is the dominant P-bearing gas (see Figure 4), and its abundance is proportional to $m$. The maximum $\mathrm{PH}_{3}$ abundance is $X_{\mathrm{PH}_{3}} \approx X_{\Sigma \mathrm{P}}$. Phosphine therefore approximately represents the total phosphorus inventory in the deep atmospheres of giant planets and $\mathrm{T}$ dwarfs. Furthermore, rapid vertical mixing and phosphine quenching from deep atmospheric regions where $\mathrm{PH}_{3}$ dominates is expected to give disequilibrium abundances of $X_{\mathrm{PH}_{3}} \approx X_{\Sigma \mathrm{P}}$ in the observable atmospheres of giant planets and $\mathrm{T}$ dwarfs (see $\S 4.3$ ).

\subsubsection{Diatomic Phosphorus, $P_{2}$ gas}

Mole fraction contours for $\mathrm{P}_{2}$ are given in Figure $5 \mathrm{c}$ as a function of $T$ and $P_{T}$. In cooler objects (e.g., giant planets and $\mathrm{T}$ dwarfs), $\mathrm{P}_{2}$ is governed by reaction (39), and the mole fraction abundance of $\mathrm{P}_{2}$ within the $\mathrm{PH}_{3}$ field is

$$
\log X_{\mathrm{P}_{2}} \approx-1.01-7474 / T-2 \log P_{T}+2[\mathrm{P} / \mathrm{H}],
$$

proportional to $P_{T}^{-2}$ and $m^{2}$. At lower total pressures $\left(\lesssim 10^{-0.48}\right.$ bar $), \mathrm{P}_{2}$ is the dominant P-bearing gas (see Figure 4), and its abundance is proportional to $m$. The maximum $\mathrm{P}_{2}$ abundance is $X_{\mathrm{P}_{2}} \approx \frac{1}{2} X_{\Sigma \mathrm{P}}$ because each molecule of $\mathrm{P}_{2}$ contains two phosphorus atoms. With increasing temperatures, $\mathrm{P}_{2}$ is replaced by $\mathrm{PH}_{2}$ via reaction (43) in the atmospheres of L dwarfs and Pegasi planets.

\subsubsection{Phosphino, $\mathrm{PH}_{2}$ gas}

Figure 5d illustrates the abundances of the $\mathrm{PH}_{2}$ radical, which is the most abundant P-bearing gas in the deep atmospheres of brown dwarfs and Pegasi planets. At lower temperatures, the $\mathrm{PH}_{2}$ abundance within the $\mathrm{PH}_{3}$ field is governed by reaction (41) and is given by

$$
\log X_{\mathrm{PH}_{2}} \approx-2.40-5444 / T-0.5 \log P_{T}+[\mathrm{P} / \mathrm{H}]
$$


proportional to $P_{T}^{-0.5}$ and $m$. When $\mathrm{P}_{2}$ is the dominant phosphorus gas, the $\mathrm{PH}_{2}$ abundance is governed by reaction (43) and is given by

$$
\log X_{\mathrm{PH}_{2}} \approx-5.19-1707 / T+0.5 \log P_{T}+0.5[\mathrm{P} / \mathrm{H}]
$$

proportional to $P_{T}^{0.5}$ and $m^{0.5}$. Equations (49) and (50) show that the $\mathrm{PH}_{2}$ abundances decrease with $P_{T}$ when $\mathrm{PH}_{3}$ dominates, and increase with $P_{T}$ when $\mathrm{P}_{2}$ dominates. This explains the curvature of the $\mathrm{PH}_{2}$ mole fraction contours in Figure 5d.

\subsection{Phosphorus Condensation Chemistry}

At low temperatures (Figure 4), equilibrium condensation of $\mathrm{NH}_{4} \mathrm{H}_{2} \mathrm{PO}_{4}$ is expected to occur via the net thermochemical reaction

$$
10 \mathrm{H}_{2} \mathrm{O}+4 \mathrm{NH}_{3}+\mathrm{P}_{4} \mathrm{O}_{6}=4 \mathrm{NH}_{4} \mathrm{H}_{2} \mathrm{PO}_{4}+4 \mathrm{H}_{2}
$$

The condensation temperature of $\mathrm{NH}_{4} \mathrm{H}_{2} \mathrm{PO}_{4}$ as a function of $P_{T}$ and metallicity is approximated by

$$
\begin{aligned}
& 10^{4} / T_{\text {cond }}\left(\mathrm{NH}_{4} \mathrm{H}_{2} \mathrm{PO}_{4}\right) \approx 29.99-0.20\left(11 \log P_{T}+10[\mathrm{O} / \mathrm{H}]+4[\mathrm{~N} / \mathrm{H}]+1[\mathrm{P} / \mathrm{H}]\right) \\
& 10^{4} / T_{\text {cond }}\left(\mathrm{NH}_{4} \mathrm{H}_{2} \mathrm{PO}_{4}\right) \approx 29.99-0.20\left(11 \log P_{T}+15[\mathrm{M} / \mathrm{H}]\right),
\end{aligned}
$$

assuming $[\mathrm{O} / \mathrm{H}]=[\mathrm{N} / \mathrm{H}]=[\mathrm{P} / \mathrm{H}]$ (see $\S 2$ ). If equilibrium were attained (which is not the case for the giant planets in our Solar System), $\mathrm{NH}_{4} \mathrm{H}_{2} \mathrm{PO}_{4}$ condensation would efficiently remove phosphorus from the upper atmospheres of giant planets and the coolest $\mathrm{T}$ dwarfs because oxygen and nitrogen abundances are typically much larger than that of phosphorus. We found that neither $\mathrm{P}_{4} \mathrm{O}_{10}$ nor elemental $\mathrm{P}$ condense under equilibrium conditions over this $P$ - $T$ range from a solar system composition gas.

\subsection{Phosphorus Chemistry in Substellar Objects}

Figures 6a-6d illustrate equilibrium phosphorus gas chemistry along model atmosphere profiles Jupiter, Gliese 229B, HD209458b, and the L dwarf as done for sulfur in Figure 3. As before, the shape of the $P-T$ profile of HD209458b (Figure 4) is responsible for the curvature in the phosphorus abundances near $1800 \mathrm{~K}$.

Using the effective temperatures for reference, the major P-bearing gases expected from thermochemical equilibrium in the observable atmospheres are: $\mathrm{P}_{4} \mathrm{O}_{6}$ in giant planets and 
cool T dwarfs $\left(T_{\text {eff }} \sim 100-1000 \mathrm{~K}\right), \mathrm{PH}_{3}$ in hot $\mathrm{T}$ dwarfs and cool L dwarfs $\left(T_{\text {eff }} \sim 1000-1400\right.$ $\mathrm{K}), \mathrm{PH}_{2}$ in hot $\mathrm{L}$ dwarfs $\left(T_{\text {eff }} \sim 1400-2000 \mathrm{~K}\right), \mathrm{P}_{2}$ in Pegasi planets such as HD209458b $\left(T_{\text {eff }} \sim 1350 \mathrm{~K}\right)$, and monatomic $\mathrm{P}$ in cool $\mathrm{M}$ dwarfs (e.g., $\left.T_{\text {eff }} \sim 2200 \mathrm{~K}\right)$. The dominant Pbearing gas changes with increasing temperature, and the major phosphorus gases at depth are: $\mathrm{PH}_{2}$ in Pegasi planets, $\mathrm{PH}_{2}$ and $\mathrm{P}$ in $\mathrm{L}$ dwarfs, $\mathrm{PH}_{3}$ and $\mathrm{PH}_{2}$ in $\mathrm{T}$ dwarfs, and $\mathrm{PH}_{3}$ in giant planets (Figure 4).

However, thermochemical equilibrium does not apply to phosphorus chemistry in the upper atmospheres of giant planets and $\mathrm{T}$ dwarfs because the conversion from $\mathrm{PH}_{3}$ to $\mathrm{P}_{4} \mathrm{O}_{6}$ is kinetically inhibited (Prinn \& Owen 1976; Barshay \& Lewis 1978; Prinn et al. 1984; FL94), and timescales for the $\mathrm{PH}_{3}$ to $\mathrm{P}_{4} \mathrm{O}_{6}$ conversion $\left(t_{\text {chem }}\right)$ are larger than typical convective mixing timescales $\left(t_{\text {mix }}\right)$ in these atmospheres (Fegley \& Prinn 1985; FL94; Fegley \& Lodders 1996). The chemical lifetime of $\mathrm{PH}_{3}$ as a function of $T$ and $P_{T}$ for solar metallicity is given in Figure 7, using $\mathrm{PH}_{3}$ destruction kinetics described by Visscher \& Fegley (2005). The quench temperature (where $t_{\text {chem }}=t_{\text {mix }}$ ) for $\mathrm{PH}_{3}$ destruction is expected to be inside the $\mathrm{PH}_{3}$ field in the deep atmospheres of giant planets and $\mathrm{T}$ dwarfs. As a result, virtually no $\mathrm{P}_{4} \mathrm{O}_{6}$ forms and $\mathrm{PH}_{3}$ is mixed upward into their observable atmospheres at abundances approximately representative of the total atmospheric phosphorus inventory $\left(X_{\mathrm{PH}_{3}} \approx X_{\Sigma \mathrm{P}}\right)$. We therefore expect $\mathrm{PH}_{3}$ (instead of $\mathrm{P}_{4} \mathrm{O}_{6}$ ) to be the major P-bearing gas in giant planets and $\mathrm{T}$ dwarfs.

Indeed, spectroscopic observations of $\mathrm{PH}_{3}$ in the upper atmospheres of Jupiter and Saturn indicate tropospheric phosphine abundances of $1.1 \mathrm{ppm}$ by volume on Jupiter (e.g., Lodders 2004b, and references therein) and 4.5 ppm by volume on Saturn (e.g., Visscher \& Fegley 2005, and references therein). These measured $\mathrm{PH}_{3}$ abundances are $\sim 30$ orders of magnitude higher than expected from thermodynamic equilibrium and imply rapid vertical mixing from deeper atmospheric levels where phosphine is more abundant. We expect $\mathrm{PH}_{3}$ abundances of $\sim 0.6 \mathrm{ppm}$ (for solar metallicity) in the upper atmospheres of Jupiter-type giant planets and cool T dwarfs such as Gliese 229B (e.g., Fegley \& Lodders 1996), and measurements of phosphine in these objects should approximately represent their bulk atmospheric phosphorus inventory. Noll \& Marley (1997) discussed the observability of gases affected by vertical mixing and concluded that the $4.3 \mu \mathrm{m}$ feature of $\mathrm{PH}_{3}$ is potentially detectable in the infrared spectra of $\mathrm{T}$ dwarfs. Photochemistry may plausibly destroy $\mathrm{PH}_{3}$ in the uppermost atmospheres of these objects (see §5), as occurs on Jupiter and Saturn.

In hotter objects, $\mathrm{PH}_{3}$ may no longer represent the total atmospheric phosphorus inventory when $\mathrm{P}$ equilibrium chemistry is established and other abundant P-bearing gases are present. Phosphine abundances of $\sim 50 \mathrm{ppb}$ (for solar metallicity) remain at the 1350 $\mathrm{K}$ level on HD209458b and $1800 \mathrm{~K}$ in the model $\mathrm{L}$ dwarf. The $\mathrm{PH}_{3}$ feature at $4.3 \mu \mathrm{m}$ is potentially detectable in these objects if it can be distinguished from nearby CO bands (Noll 
\& Marley 1997; Saumon et al. 2003).

The abundant $\mathrm{P}$-bearing gases at higher atmospheric temperatures include $\mathrm{P}_{2}, \mathrm{PH}, \mathrm{PH}_{2}$, $\mathrm{PH}_{3}$, and HCP (Figures 6a-6d). The phosphino radical $\left(\mathrm{PH}_{2}\right)$ is the dominant P-bearing gas in the observable atmosphere of the model $\mathrm{L}$ dwarf and in the deep atmospheres of $\mathrm{T}$ dwarfs and Pegasi planets. However, $\mathrm{PH}_{2}$ only represents about half of the total atmospheric

phosphorus inventory because other P-bearing gases remain relatively abundant within the $\mathrm{PH}_{2}$ field. Equilibrium $\mathrm{PH}_{2}$ abundances of $\sim 1 \mathrm{ppb}, \sim 50 \mathrm{ppb}$, and $\sim 300 \mathrm{ppb}$ are expected (for solar metallicity) in the observable atmospheres of $\mathrm{T}$ dwarfs, Pegasi planets, and $\mathrm{L}$ dwarfs, respectively.

As temperatures decrease, $\mathrm{PH}_{2}$ is replaced by $\mathrm{PH}_{3}$ (in Gliese 229B, Figure 6b) and/or $\mathrm{P}_{2}$ (in HD209458b and the L dwarf, Figures 6c-6d) as the major P-bearing gas, depending on the position of the atmospheric $\mathrm{P}-\mathrm{T}$ profile relative to the $\mathrm{PH}_{3}-\mathrm{PH}_{2}-\mathrm{P}_{2}$ triple point (see Figure 4 and §4.1). Although $\mathrm{P}_{2}$ is expected to be the dominant P-bearing gas in the observable atmospheres of Pegasi planets $\left(X_{\mathrm{P}_{2}} \sim 0.2 \mathrm{ppm}\right.$ at $\left.1350 \mathrm{~K}\right)$ and the upper atmospheres of $\mathrm{L}$ dwarfs, the $\mathrm{P}_{2}$ bands expected near $0.2 \mu \mathrm{m}$ (Carroll \& Mitchell 1975) may be very difficult to detect in these objects. At temperatures below $\sim 1000 \mathrm{~K}, \mathrm{P}_{2}$ is converted into $\mathrm{P}_{4} \mathrm{O}_{6}$, which is plausibly destroyed by photochemical processes in the uppermost atmospheres of $\mathrm{L}$ dwarfs and Pegasi planets (see $§ 5$ ).

The abundances of PH and HCP are negligible in the observable atmospheres of giant planets and $\mathrm{T}$ dwarfs. In warmer objects, these gases have equilibrium abundances (at solar metallicity) of $\sim 2 \mathrm{ppb}(\mathrm{PH})$ and $\sim 20 \mathrm{ppb}(\mathrm{HCP})$ on HD209458b (at $1350 \mathrm{~K}$ ), and $\sim 50$ $\mathrm{ppb}(\mathrm{PH})$ and $\sim 15 \mathrm{ppb}(\mathrm{HCP})$ in the $\mathrm{L}$ dwarf model atmosphere (at $1800 \mathrm{~K})$.

Under equilibrium conditions, $\mathrm{NH}_{4} \mathrm{H}_{2} \mathrm{PO}_{4}$ cloud formation would be expected near the $400 \mathrm{~K}$ level in the upper atmosphere of Jupiter (cf. Barshay \& Lewis 1978; FL94), but is precluded by quenching of $\mathrm{PH}_{3}$ (see above). Condensation of $\mathrm{NH}_{4} \mathrm{H}_{2} \mathrm{PO}_{4}$ is not expected in the warmer atmospheres of Gliese 229B, HD209458b, and the L dwarf because their P-T profiles do not intersect the $\mathrm{NH}_{4} \mathrm{H}_{2} \mathrm{PO}_{4}$ condensation curve (Figure 4).

\section{Thermochemistry and Photochemistry}

So far, our treatment of sulfur and phosphorus chemistry assumes the establishment of thermochemical equilibrium. The exception is phosphine, for which the kinetics of its destruction mechanism and convective vertical mixing must be considered for determining $\mathrm{PH}_{3}$ abundances (§4.3). However, we must also consider photochemical reactions in the uppermost atmospheres of planets and brown dwarfs that are companions to stars. If ul- 
traviolet flux causes photochemical reactions, the thermochemical reactions will be driven out of equilibrium. Photochemistry may also play a role in isolated brown dwarfs if their coronae are warm enough to produce an ultraviolet flux (Yelle 1999).

For example, in Jupiter's troposphere the major C-, N-, S- and O-bearing gases expected from thermochemical equilibrium are $\mathrm{CH}_{4}, \mathrm{NH}_{3}, \mathrm{H}_{2} \mathrm{~S}$, and $\mathrm{H}_{2} \mathrm{O}$, respectively (FL94). However, Jupiter's stratosphere contains photochemically produced hydrocarbons such as $\mathrm{C}_{2} \mathrm{H}_{6}, \mathrm{C}_{2} \mathrm{H}_{2}$, and $\mathrm{C}_{2} \mathrm{H}_{4}$ (Gladstone et al. 1996). Hence we must examine the relative roles of thermochemistry and photochemistry on $\mathrm{S}$ and $\mathrm{P}$ compounds in brown dwarfs, EGPs, and related objects.

\subsection{Thermochemistry in Substellar Objects}

Thermochemical equilibrium is readily achieved in the hot, deep atmospheres of substellar objects because gas phase reaction rates are generally much faster than convective mixing rates (i.e., $t_{c h e m} \ll t_{m i x}$ ). To illustrate this, we consider the kinetics of the following elementary reactions:

$$
\begin{aligned}
\mathrm{H}+\mathrm{H}_{2} \mathrm{~S} & \rightarrow \mathrm{SH}+\mathrm{H}_{2}, \\
\mathrm{SH}+\mathrm{CO} & \rightarrow \mathrm{OCS}+\mathrm{H}, \\
\mathrm{S}+\mathrm{H}_{2} \mathrm{~S} & \rightarrow \mathrm{SH}+\mathrm{SH}, \\
\mathrm{Na}+\mathrm{HCl} & \rightarrow \mathrm{NaCl}+\mathrm{H}, \\
\mathrm{PH}+\mathrm{PH}_{2} & \rightarrow \mathrm{PH}_{3}+\mathrm{P}, \\
\mathrm{H}+\mathrm{PH}_{3} & \rightarrow \mathrm{PH}_{2}+\mathrm{H}_{2} .
\end{aligned}
$$

Here we use reaction (53) as an example for computing $t_{c h e m}$. The rate of disappearance of $\mathrm{H}_{2} \mathrm{~S}$ in reaction (53) is given by

$$
\frac{d\left[\mathrm{H}_{2} \mathrm{~S}\right]}{d t}=-k_{53}[\mathrm{H}]\left[\mathrm{H}_{2} \mathrm{~S}\right]
$$

where $k_{53}\left(\mathrm{~cm}^{3}\right.$ molecules $\left.{ }^{-1} \mathrm{~s}^{-1}\right)$ is the rate coefficient for reaction (53) and $\left[\mathrm{H}_{2} \mathrm{~S}\right]$ and $[\mathrm{H}]$ are the molecular number densities (molecules $\mathrm{cm}^{-3}$ ) for $\mathrm{H}_{2} \mathrm{~S}$ and $\mathrm{H}$. The chemical lifetime for $\mathrm{H}_{2} \mathrm{~S}$ is defined as

$$
t_{\text {chem }}\left(\mathrm{H}_{2} \mathrm{~S}\right)=-\frac{\left[\mathrm{H}_{2} \mathrm{~S}\right]}{d\left[\mathrm{H}_{2} \mathrm{~S}\right] / d t}=\frac{1}{k_{53}[\mathrm{H}]},
$$

and is the time required for a $1 / e$ reduction in the $\mathrm{H}_{2} \mathrm{~S}$ abundance. Representative chemical lifetimes for reactions (53)-(58) at 1 bar total pressure and 1000, 1500, and $2000 \mathrm{~K}$ are listed in Table 1. Although the short chemical lifetimes in Table 1 indicate that these reactions 
proceed rapidly, we must also consider vertical mixing rates to determine if equilibrium is established. The timescale for convective mixing, $t_{\text {mix }}$ is approximated by

$$
t_{\text {mix }} \sim H^{2} / K_{e d d y}
$$

where $K_{\text {eddy }}$ is the eddy diffusion coefficient. The pressure scale height, $H$, is given by

$$
H=R T / \mu g
$$

where $R$ is the gas constant, $\mu$ is the mean molecular weight of the gas, and $g$ is gravity. For a solar system composition gas, $\mu \approx 2.3 \mathrm{~g} \mathrm{~mol}^{-1}$. A convective timescale of $t_{\text {mix }} \sim 10^{6}$ seconds is expected near the $1000 \mathrm{~K}$ level on Jupiter, using $H \sim 140 \mathrm{~km}(\log g=3.4)$ and $K_{\text {eddy }} \sim 10^{8} \mathrm{~cm}^{2} \mathrm{~s}^{-1}$ (Fegley \& Prinn 1988). On Gliese 229B, we estimate $t_{\text {mix }} \sim 10^{7}$ seconds at the $1000 \mathrm{~K}$ level, assuming $H \sim 3.6 \mathrm{~km}\left(\log g=5.0\right.$; Saumon et al. 2000) and $K_{\text {eddy }} \sim 10^{4}$ $\mathrm{cm}^{2} \mathrm{~s}^{-1}$ (Griffith \& Yelle 1999). Because of its low gravity ( $\log g=3.0$; Iro et al. 2005) HD209458b has large mixing times of $\sim 10^{7}$ to $10^{11}$ seconds at the $1000 \mathrm{~K}$ level, depending on the assumed $K_{\text {eddy }}$ value $\left(\sim 10^{8}\right.$ to $\left.10^{4} \mathrm{~cm}^{2} \mathrm{~s}^{-1}\right)$. These timescales for convective mixing are typically many orders of magnitude greater than the chemical lifetimes listed in Table 3 (i.e., $\left.t_{\text {chem }} \ll t_{m i x}\right)$. We therefore expect the rapid establishment of thermochemical equilibrium in the deep atmospheres of substellar objects. In instances where the rate of vertical mixing equals or exceeds the rate of chemical reactions $\left(t_{c h e m} \geq t_{m i x}\right)$, disequilibrium species (e.g., $\mathrm{PH}_{3}$, see §4.3) are mixed into the upper atmospheres of substellar objects, as occurs on Jupiter and Saturn (e.g., CO, HCN, $\mathrm{PH}_{3}, \mathrm{GeH}_{4}, \mathrm{AsH}_{3}$; FL94) and Gliese 229B (e.g. CO, $\mathrm{PH}_{3}, \mathrm{~N}_{2}$; Fegley \& Lodders 1996; Griffith \& Yelle 1999; Saumon et al. 2000).

\subsection{Photochemistry on Pegasi Planets}

In order to examine the relative importance of photochemical vs. thermochemical processes in substellar objects, we consider an extreme example: the strongly irradiated upper atmosphere of HD209458b. This Pegasi planet orbits a solar-type star at $0.05 \mathrm{AU}$ and receives a stellar UV flux $\sim 10,000$ times that for Jupiter (e.g., Liang et al. 2003). To determine the depth in the atmosphere where thermochemical processes become important, we compared the thermochemical equilibrium abundances of the reactive species $\mathrm{OH}, \mathrm{O}$, and $\mathrm{H}$ in our model with photochemical equilibrium abundances from Liang et al. (2003) for HD209458b. Plots comparing photochemical (dotted lines) and thermochemical (solid lines) abundances for these reactive species are shown in Figure 8, using the $P$ - $T$ profile for HD209458b from Figure 1 of Liang et al. (2003).

At very low pressures, in the uppermost atmosphere of HD209458b, photochemistry produces excess disequilibrium abundances of $\mathrm{OH}, \mathrm{O}$, and $\mathrm{H}$, primarily via $\mathrm{H}_{2} \mathrm{O}$ photoly- 
sis (Liang et al. 2003). Thermochemistry becomes increasingly important with depth, as pressures and temperatures increase and the available stellar flux decreases. Eventually, the predicted thermochemical abundances surpass the photochemical abundances, indicating the establishment of equilibrium chemistry. In other words, the photochemical reactions are no longer driving the thermochemical reactions out of equilibrium. As shown in Figure 8, this crossover occurs near the $\sim 1$ to 10 mbar levels $(T \sim 980$ to $1140 \mathrm{~K}$ ) for the reactive species $\mathrm{OH}, \mathrm{O}$, and $\mathrm{H}$. Thermochemical processes are therefore expected to be important at pressures of $\sim 10$ mbar and higher on HD209458b, consistent with results showing that most of the incoming stellar flux is absorbed by the 1 bar level $(T \sim 1640 \mathrm{~K})$ in its atmosphere (Iro

et al. 2005). Furthermore, Fortney et al. (2005, 2006) point out that the infrared spectra of Pegasi planets appear to be most sensitive to opacity near 10 to 100 mbar ( $T \sim 1140$ to 1400 $\mathrm{K}$ ). This suggests that thermochemical models will provide a useful basis for interpreting and guiding observations of Pegasi planet atmospheres.

\section{Summary}

Thermochemistry governs the chemical behavior of sulfur and phosphorus species in the hot, deep atmospheres of substellar objects. Hydrogen sulfide is the most abundant sulfurbearing gas throughout substellar atmospheres, and observations of $\mathrm{H}_{2} \mathrm{~S}$ in these objects should provide a good estimate of their atmospheric sulfur content. The condensation of metal sulfide clouds slightly lowers the atmospheric $\mathrm{H}_{2} \mathrm{~S}$ abundance to $\sim 91 \%$ of the total $\mathrm{S}$ inventory. These clouds also affect opacity by introducing condensed particles and by removing absorbing gases from the observable atmosphere. Mercapto ( $\mathrm{SH}$ ) and SiS are the next most abundant sulfur gases after $\mathrm{H}_{2} \mathrm{~S}$, and the relative importance of SiS increases with increasing effective temperature. Furthermore, the maximum SiS abundance occurs near the Mg-silicate cloud base and is a potential tracer of weather in Pegasi planets and L dwarfs.

Phosphorus speciation is considerably more complex than that for C, N, O, or S, and several phosphorus gases become relatively abundant at high temperatures. Disequilibrium abundances of $\mathrm{PH}_{3}$ are expected in the upper atmospheres of giant planets and $\mathrm{T}$ dwarfs via rapid vertical mixing from deeper levels. In addition, phosphine abundances in giant planets and $\mathrm{T}$ dwarfs are expected to approximately represent their atmospheric phosphorus inventories. In Pegasi planets and $\mathrm{L}$ dwarfs, $\mathrm{P}_{2}$ is the dominant phosphorus gas until replaced by $\mathrm{P}_{4} \mathrm{O}_{6}$ at low temperatures or $\mathrm{PH}_{2}$ at high temperatures. Phosphino $\left(\mathrm{PH}_{2}\right)$ is the most abundant phosphorus gas in the deep atmospheres of brown dwarfs and Pegasi planets.

This work was supported by the NASA Planetary Atmospheres Program. Work by KL 
was supported by NSF grant AST 04-06963.

\section{A. Additional Compounds}

Here we list additional sulfur and phosphorus compounds investigated but not discussed in detail above. This list includes unstable condensates and minor gases predicted to have very low abundances in a solar system composition gas at temperatures and total pressures relevant for substellar atmospheres. Depending on the prevailing sulfur, carbon, and phosphorus chemistry, the abundances of key gases are $P_{T}$ independent: $\mathrm{H}_{2} \mathrm{~S}_{2}$ within the $\mathrm{H}_{2} \mathrm{~S}$ field; OCS, CS, and $\mathrm{CS}_{2}$ within the $\mathrm{CO}$ field; $\mathrm{CH}_{3} \mathrm{SH}$ within the $\mathrm{CH}_{4}$ field; $\mathrm{HPO}, \mathrm{PH}$, and $\mathrm{PN}$ within the $\mathrm{P}_{2}$ field. However, their abundances are generally too low to serve as useful temperature probes in brown dwarf or EGP atmospheres. Some gases $\left(\mathrm{H}_{2} \mathrm{~S}_{2}, \mathrm{CH}_{3} \mathrm{SH}\right)$ are potentially detectable via deep atmospheric entry probes on Jupiter and Saturn (FL94).

For a given metallicity, relatively constant OCS abundances are expected throughout the atmospheres of CO-dominated objects; however, maximum OCS abundances are only $\sim 1 \mathrm{ppb}$ (for solar metallicity) in L dwarfs and Pegasi planets. The equilibrium abundances of P, PO, and PS generally increase with $T$ and decrease with $P_{T}$. These gases only become important at lowest total pressures considered here (see Figure 4). The behavior of HCP is similar to that of $\mathrm{PH}_{2}$; maximum $\mathrm{HCP}$ abundances are $\sim 50 \mathrm{ppb}$ (for solar metallicity) over the $P-T$ range considered here.

\section{Sulfur}

$\mathrm{S}_{3}, \mathrm{~S}_{4}, \mathrm{~S}_{2} \mathrm{O}, \mathrm{SO}, \mathrm{SO}_{2}, \mathrm{SO}_{3}, \mathrm{SOH}, \mathrm{HSO}, \mathrm{H}_{2} \mathrm{SO}, \mathrm{H}_{2} \mathrm{SO}_{4}, \mathrm{SF}, \mathrm{SF}_{2}, \mathrm{H}_{2} \mathrm{~S}_{2}, \mathrm{OCS}, \mathrm{CS}, \mathrm{CS}_{2}, \mathrm{CH}_{3} \mathrm{SH}$, NS, PS, K ${ }_{2}$ S, CaS, FeS, MgS, MnS, TiS, VS, ZrS, $\mathrm{SiS}_{2}, \mathrm{TiS}_{2}, \mathrm{ZrS}_{2}$, S(s,l), OCS(s,l), $\mathrm{SO}_{2}(\mathrm{~s}, 1)$

\section{Phosphorus}

$\mathrm{P}_{3}, \mathrm{P}_{4}, \mathrm{PO}, \mathrm{PO}_{2}, \mathrm{P}_{2} \mathrm{O}_{3}, \mathrm{P}_{2} \mathrm{O}_{4}, \mathrm{P}_{2} \mathrm{O}_{5}, \mathrm{P}_{3} \mathrm{O}_{6}, \mathrm{P}_{4} \mathrm{O}_{7}, \mathrm{P}_{4} \mathrm{O}_{8}, \mathrm{P}_{4} \mathrm{O}_{9}, \mathrm{P}_{4} \mathrm{O}_{10}, \mathrm{PCl}, \mathrm{PCl}_{2}, \mathrm{PCl}_{3}$, $\mathrm{PF}, \mathrm{PF}_{2}, \mathrm{PF}_{3}, \mathrm{HPO}, \mathrm{HCP}, \mathrm{CP}, \mathrm{PH}, \mathrm{PN}, \mathrm{PS}, \mathrm{P}(\mathrm{s}), \mathrm{P}_{4} \mathrm{O}_{10}(\mathrm{~s}, \mathrm{l})$

\section{REFERENCES}

Aoki, W., Tsuji, T., \& Ohnaka, K. 1998, A\&A, 340, 222

Arthur, N. L., \& Cooper, I. A. 1997, J. Chem. Soc. Faraday Trans., 93, 521 
Barman, T. S., Hauschildt, P. H., \& Allard, F. 2005, ApJ, 632, 1132

Barshay, S. S., \& Lewis, J. S. 1978, Icarus, 33, 593

Baulch, D. L., et al. 1992, J. Phys. Chem Ref. Data, 21, 411

Berdyugina, S. V., \& Livingston, W. C. 2002, A\&A, 387, L6

Bézard, B., Marten, A., Baluteau, J. P., Gautier, D., Flaud, J. M., \& Camy-Peyret, C. 1983, Icarus, 55, 259

Burgasser, A. J., Marley, M. S., Ackerman, A. S., Saumon, D., Lodders, K., Dahn, C. C., Harris, H. C., \& Kirkpatrick, J. D. 2002, ApJ, 571, L151

Burrows, A., Hubbard, W. B., Lunine, J. I., Marley, M. S. \& Saumon, D. 2000, in Protostars and Planets IV, ed. V. Mannings, A. P. Boss, \& S. S. Russell (Tuscon: Univ. of Arizona Press), 1339

Burrows, A., Marley, M. S., \& Sharp, C. M. 2000, ApJ, 531, 438

Burrows, A., Sudarsky, D., \& Hubeny I. 2006, ApJ, 640, 1063

Carroll, P. K., \& Mitchell, P. I. 1975, Proc. Roy. Soc. Lon. A, 342, 93

Charbonneau, D., Brown, T. M., Noyes, R. W., \& Gilliland, R. L. 2002, ApJ, 568, 377

Chase, M. W. 1999, J. Phys. Chem. Ref. Data, 28, monograph no. 9

Chen, Y. Q., Nissen, P. E., Zhao, G., Zhang, H. W., \& Benoni, T. 2000, A\&AS, 141, 491

Edvardsson, B., Andersen, J., Gustafsson, B., Lambert, D. L., Nissen, P. E., \& Tomkin, J. 1993, A\&A, 275, 101

Ecuvillon, A., Israelian, G., Santos, N. C., Mayor, M., Villar, V., \& Bihain, G. 2004, A\&A, 426,619

Fegley, B. Jr., Gautier, D., Owen, T., \& Prinn, R. G. 1991, in Uranus, ed. J. T. Bergstralh, E. D. Miner, \& M. S. Matthews (Tuscon: Univ. of Arizona Press), 147

Fegley, B., Jr., \& Lewis, J. S. 1979, Icarus, 38, 166

Fegley, B., Jr., \& Lewis, J. S. 1980, Icarus, 41, 439

Fegley, B., Jr., \& Lodders, K. 1994, Icarus, 110, 117; FL94 
Fegley, B., Jr., \& Lodders, K. 1996, ApJ, 472, L37

Fegley, B., Jr., \& Prinn, R. G. 1985, ApJ, 299, 1067

Fegley, B., Jr., \& Prinn, R. G. 1988, ApJ, 324, 621

Fortney, J. J., Sudarsky, D., Hubeny, I., Cooper, C. S., Hubbard, W. B., Burrows, A., \& Lunine, J. I. 2003, ApJ, 589, 615

Fortney, J. J., Marley, M. S., Lodders, K., Saumon, D. \& Freedman, R. 2005, ApJ, 627, L69

Fortney, J. J., Saumon, D., Marley, M. S., Lodders, K., \& Freedman, R. S. 2006, ApJ, 642, 495

Gladstone, G. R., Allen, M., \& Yung, Y. L. 1996, Icarus, 119, 1

Griffith, C. A., \& Yelle, R. V. 1999, ApJ, 519, L85

Gurvich, L. V., Veyts, I. V., \& Alcock, C. B. 1989-1994, Thermodynamic Properties of Individual Substances, 4th ed., 3 vols. (New York: Hemisphere Publishing)

Gustafsson, B., Karlsson, T., Olsson, E., Edvardsson, B., \& Ryde, N. 1999, A\&A, 342, 426

Huang, C., Zhao, G., Zhang, H. W., \& Chen, Y. Q. 2005, MNRAS, 363, 71

Husain, D., \& Marshall, P. 1986, Int. J. Chem. Kin., 18, 83

Iro, N., Bézard, B., \& Guillot, T. 2005, A\&A, 436, 719

Kirkpatrick, J. D., et al. 1999, ApJ, 519, 802

Kurbanov, M. A., \& Mamedov, Kh. F. 1995, Kinet. Catal. 36, 455

Larson, H. P., Bjoraker, G. L., Davis, D. S., \& Hofmann, R. 1984, Icarus, 60, 621

Liang, M. C., Parkinson, C. D., Lee, A. Y. T., Yung, Y. L., \& Seager, S. 2003, ApJ, 596, L247

Liebert, J., Reid, I. N., Burrows, A., Burgasser, A. J., Kirkpatrick, J. D., \& Gizis, J. E. 2000, ApJ, 533, L155

Lewis, J. S. 1969, Icarus, 10, 393

Lewis, J. S. 1969, Icarus, 10, 365

Lodders, K. 1999a, ApJ, 519, 793 
Lodders, K. 1999b, J. Phys. Chem. Ref. Data, 28, 1705

Lodders, K. 2002, ApJ, 577, 974

Lodders, K., \& Fegley, B., Jr. 2002, Icarus, 155, 393; LF02

Lodders, K. 2003, ApJ, 591, 1220

Lodders, K. 2004a, J. Phys. Chem Ref. Data, 33, 357

Lodders, K. 2004b, ApJ, 611, 587

Lodders, K., \& Fegley, B., Jr. 2006, in Astrophysics Update 2, ed. J. W. Mason (SpringerPraxis)

Marley, M. S., Saumon, D., Guillot, T., Freedman, R. S., Hubbard, W. B., Burrows, A., \& Lunine, J. I. 1996, Science, 272, 191

McLean, I. S., McGovern, M. R., Burgasser, A. J., Kirkpatrick, J. D., Prato, L., \& Kim, S. S. 2003, ApJ, 596, 561

Niemann H. B., et al. 1998, J. Geophys. Res., 103, 22831

Noll, K. S., et al. 1995, Science, 267, 1307

Noll, K. S., \& Marley, M. S. 1997, ASP Conf. Ser. 119: Planets Beyond the Solar System and the Next Generation of Space Missions, 119, 115

Prinn, R. G., \& Owen, T. 1976, in Jupiter, ed. T. Gehrels (Tuscon: Univ. of Arizona Press), 319

Prinn, R. G., \& Olaguer, E. P. 1981, J. Geophys. Res., 86, 9895

Prinn, R. G., Larson, H. P., Caldwell, J. J., \& Gautier, D. 1984, in Saturn, ed. T. Gehrels \& M. S. Matthews (Tuscon: Univ. of Arizona Press), 88

Robie, R. A., \& Hemingway, B. S. 1995, US Geological Survey Bull. 2131

Samland, M. 1998, ApJ, 496, 155

Saumon, D., Geballe, T. R., Leggett, S. K., Marley, M. S., Freedman, R. S., Lodders, K., Fegley, B., Jr., \& Sengupta, S. K. 2000, ApJ, 541, 374

Saumon, D., Marley, M. S., \& Lodders, K. 2003, arXiv:astro-ph/0310805 
Smith, V. V., Cunha, K., \& King, J. R. 2001, AJ, 122, 370

Timmes, F. X., Woosley, S. E., \& Weaver, T. A. 1995, ApJS, 98, 617

Tsuji, T. 1973, A\&A, 23, 411

Tsuji, T., Ohnaka, K., \& Aoki, W. 1996, A\&A, 305, L1

Twarowski, A. 1995, Combust. Flame, 102, 41

Visscher, C., \& Fegley, B, Jr. 2005, ApJ, 623, 1221

West, R. A., Baines, K. H., Friedson, A. J., Banfield, D., Ragent, B., \& Taylor, F. W. 2004, in Jupiter, ed. F. Bagenal, T. E. Dowling, \& W. B. McKinnon (Cambridge: Cambridge Univ. Press), 79

Woiki, D., \& Roth, P. 1994, J. Phys. Chem., 98, 12958

Wong, M. H., Mahaffy, P. R., Atreya, S. K., Niemann, H. B., \& Owen, T. C. 2004, Icarus, 171,153

Yamamura I., Kawaguchi, K., \& Ridgeway, S. T. 2000, ApJ, 528, L33

Yelle, R. 1999, in From Giant Planets to Cool Stars, ASP Conference Series, Vol. 212, ed. C. A. Griffith \& M. S. Marley (San Francisco: ASP), 267

Yoshimura, M, Koshi, M., Matsui, H., Kamiya, K., \& Umeyama, H. 1992, Chem. Phys. Lett., 189, 199

Zahnle, K., Mac Low, M.-M., Lodders, K., \& Fegley, B. 1995, Geophys. Res. Lett., 22, 1593 
Table 1. Equilibrium Condensation Temperatures of Sulfur-Bearing Compounds

\begin{tabular}{ccccc}
\hline \hline object & $\mathrm{MnS}$ & $\mathrm{Na}_{2} \mathrm{~S}$ & $\mathrm{ZnS}$ & $\mathrm{NH}_{4} \mathrm{SH}$ \\
\hline Jupiter & 1800 & 1370 & 970 & 220 \\
Gliese 229B & 1380 & 1000 & 780 & $\ldots$ \\
HD209458b & 1260 & $\sim 800^{\mathrm{a}}$ & $\ldots$ & $\ldots$ \\
L dwarf & 1270 & $\ldots$ & $\ldots$ & $\ldots$ \\
M dwarf & $\ldots$ & $\ldots$ & $\ldots$ & $\ldots$ \\
\hline
\end{tabular}

Note. - Condensation temperatures computed using $[\mathrm{M} / \mathrm{H}] \approx+0.5$ for Jupiter, $[\mathrm{M} / \mathrm{H}]$ $\approx-0.3$ for Gliese $229 \mathrm{~B}$, and $[\mathrm{M} / \mathrm{H}] \approx 0$ for HD209458b and the model L dwarf.

${ }^{a}$ night-side condensation

Table 2. Phosphorus Equal Abundance "Triple Points" in a Solar Metallicity Gas

\begin{tabular}{ccc}
\hline \hline triple point & $T, \mathrm{~K}$ & $\log \left(P_{T}\right.$, bar $)$ \\
\hline $\mathrm{PH}_{3}-\mathrm{P}_{4} \mathrm{O}_{6}-\mathrm{P}_{2}$ & 1101 & -1.20 \\
$\mathrm{PH}_{3}-\mathrm{PH}_{2}-\mathrm{P}_{2}$ & 1330 & -0.48 \\
$\mathrm{P}_{2}-\mathrm{PO}-\mathrm{PS}$ & 1389 & -3.93 \\
$\mathrm{P}_{2}-\mathrm{PH}-\mathrm{PO}$ & 1780 & -1.26 \\
$\mathrm{PH}_{2}-\mathrm{P}-\mathrm{PO}$ & 1811 & -1.20 \\
\hline \multicolumn{4}{c}{} \\
a e.g., where $X_{\mathrm{A}}=X_{\mathrm{B}}=X_{\mathrm{C}}$ for \\
phosphorus-bearing gases $\mathrm{A}, \mathrm{B}, \mathrm{C}$.
\end{tabular}


Table 3. Representative Chemical Lifetimes at 1 bar pressure

\begin{tabular}{cccccl}
\hline \hline \multicolumn{5}{c}{ chemical lifetime, $\mathrm{s}$} & \\
reaction & $t_{\text {chem }}$ & $1000 \mathrm{~K}$ & $1500 \mathrm{~K}$ & $2000 \mathrm{~K}$ & \multicolumn{1}{c}{ kinetic data } \\
\hline 53 & $t_{\text {chem }}\left(\mathrm{H}_{2} \mathrm{~S}\right)$ & $10^{0.4}$ & $10^{-3.8}$ & $10^{-5.9}$ & Yoshimura et al. (1992) \\
54 & $t_{\text {chem }}(\mathrm{SH})$ & $10^{2.7}$ & $10^{0.2}$ & $10^{-0.2}$ & Kurbanov \& Mamedov (1995) \\
55 & $t_{\text {chem }}(\mathrm{S})$ & $10^{1.7}$ & $10^{-2.3}$ & $10^{-4.3}$ & Woiki \& Roth (1994) \\
56 & $t_{\text {chem }}(\mathrm{Na})$ & $10^{1.4}$ & $10^{-1.6}$ & $10^{-1.8}$ & Husain \& Marshall (1986) \\
57 & $t_{\text {chem }}(\mathrm{PH})$ & $10^{4.2}$ & $10^{1.2}$ & $10^{1.0}$ & Twarowski (1995) \\
58 & $t_{\text {chem }}\left(\mathrm{PH}_{3}\right)$ & $10^{0.4}$ & $10^{-3.5}$ & $10^{-5.4}$ & Arthur \& Cooper (1997) \\
\hline
\end{tabular}

Note. - Convective mixing timescales (in seconds) are $t_{\text {conv }} \sim 10^{6.3}(1000 \mathrm{~K}), 10^{6.6}$ $(1500 \mathrm{~K})$, and $10^{6.9}(2000 \mathrm{~K})$ for Jupiter, $10^{7.1}(1000 \mathrm{~K}), 10^{7.5}(1500 \mathrm{~K})$, and $10^{7.7}$ $(2000 \mathrm{~K})$ for Gliese $229 \mathrm{~B}$, and $10^{7.1}$ to $10^{11.1}(1000 \mathrm{~K}), 10^{7.5}$ to $10^{11.5}(1500 \mathrm{~K})$, and $10^{7.7}$ to $10^{11.7}$ (2000 K) for HD209458b. See $\S 5.1$ for details. 


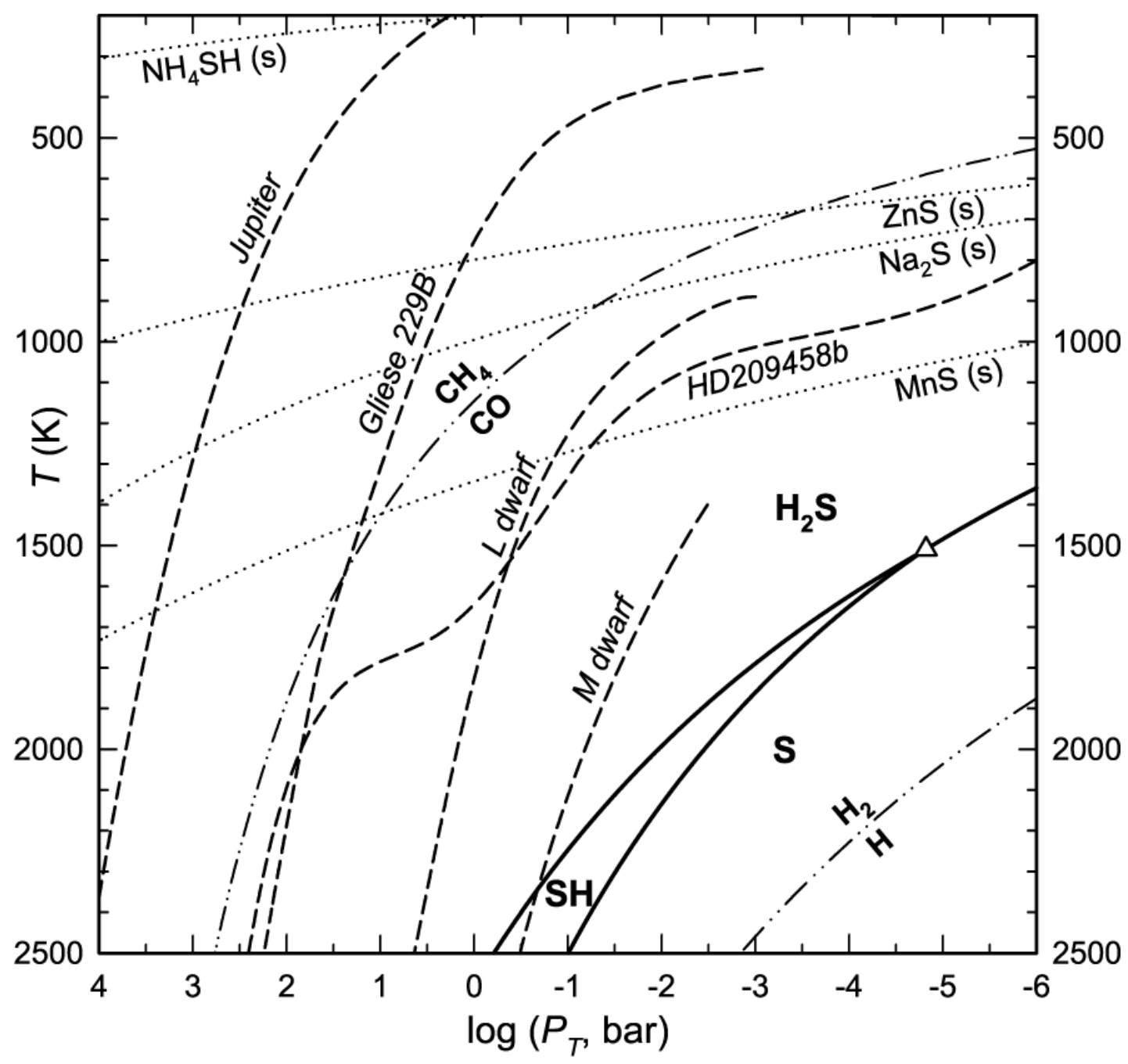

Fig. 1.- Overview of sulfur chemistry as a function of temperature and pressure in a solar system composition gas. The solid lines indicate where major S-bearing gases have equal abundances. The triangle denotes the position of the triple point where $\mathrm{H}_{2} \mathrm{~S}$, SH, and S have equal abundances. Also shown are condensation curves for S-bearing compounds (dotted lines) and the $\mathrm{H}_{2}=\mathrm{H}$ and $\mathrm{CH}_{4}=\mathrm{CO}$ equal abundance lines (dash-dot lines). Atmospheric profiles (dashed lines) are given for Jupiter $\left(T_{\text {eff }}=124 \mathrm{~K}\right)$, Gliese $229 \mathrm{~B}\left(T_{\text {eff }}=960 \mathrm{~K}\right)$, $\operatorname{HD} 209458 \mathrm{~b}\left(T_{\text {eff }}=1350 \mathrm{~K}\right)$, an L dwarf $\left(T_{\text {eff }}=1800 \mathrm{~K}\right)$, and an $\mathrm{M} \mathrm{dwarf}\left(T_{\text {eff }}=2200 \mathrm{~K}\right)$. 

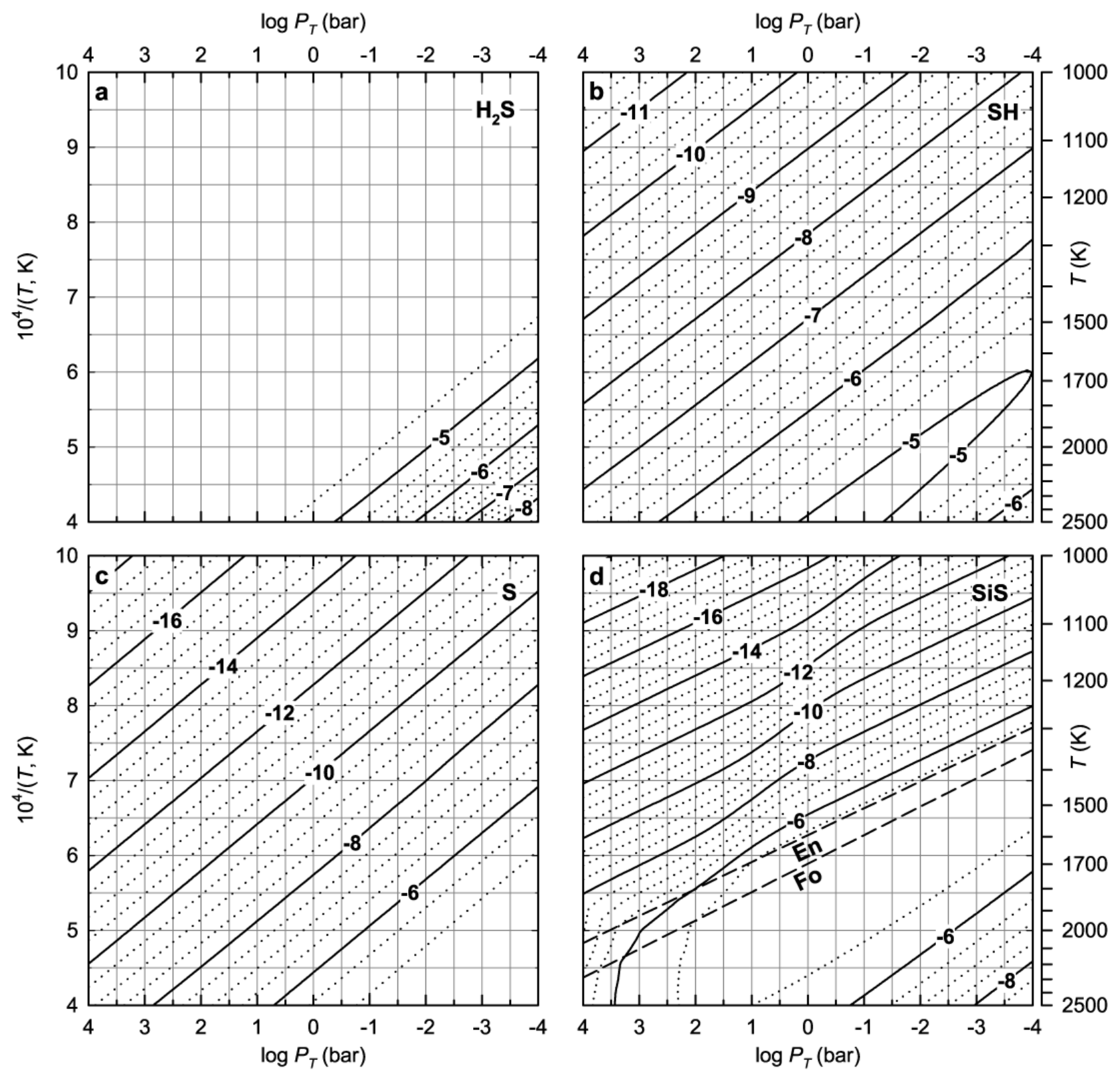

Fig. 2.- Mole fraction contours (on a logarithmic scale) for (a) hydrogen sulfide $\left(\mathrm{H}_{2} \mathrm{~S}\right)$, (b) mercapto radical (SH), (c) monatomic sulfur ( $\mathrm{S}$ ), (d) silicon sulfide ( $\mathrm{SiS}$ ) as a function of pressure and temperature in a solar metallicity gas. The dashed lines labeled Fo and En in the SiS plot indicate the equilibrium condensation temperatures of forsterite $\left(\mathrm{Mg}_{2} \mathrm{SiO}_{4}\right)$ and enstatite $\left(\mathrm{MgSiO}_{3}\right)$, respectively. 

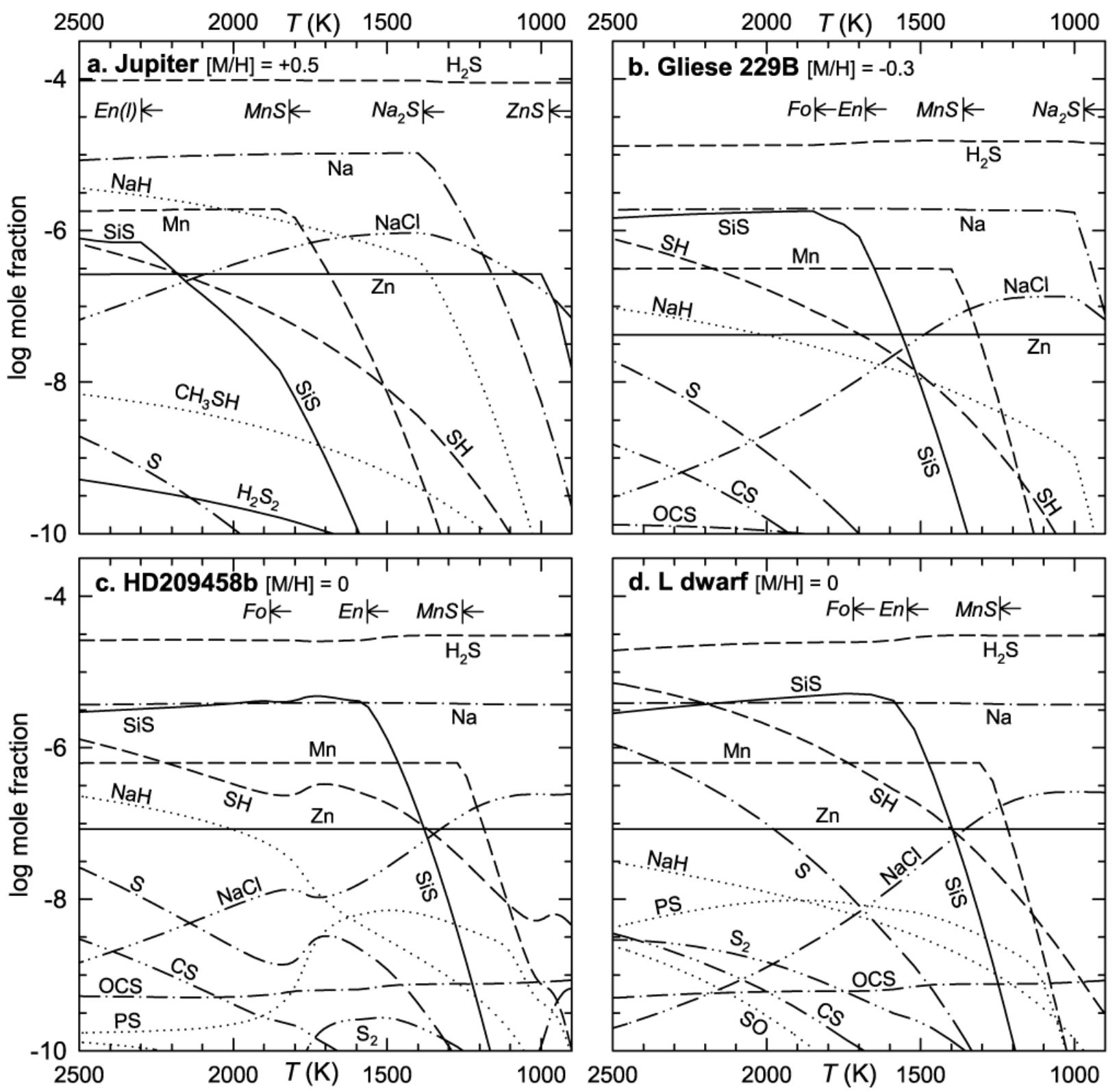

Fig. 3.- Sulfur chemistry along representative atmospheric pressure-temperature profiles from 900 to $2500 \mathrm{~K}$ for (a) Jupiter $([\mathrm{M} / \mathrm{H}] \approx+0.5)$, (b) Gliese 229B $([\mathrm{M} / \mathrm{H}] \approx-0.3)$, (c) $\operatorname{HD} 209458 \mathrm{~b}([\mathrm{M} / \mathrm{H}] \approx 0)$, and $(\mathrm{d})$ an $\mathrm{L} \operatorname{dwarf}\left([\mathrm{M} / \mathrm{H}] \approx 0 ; T_{\text {eff }}=1800 \mathrm{~K}\right)$, assuming uniform elemental enrichments and depletions. Also shown are the calculated condensation temperatures of forsterite $\left(\mathrm{Fo} ; \mathrm{Mg}_{2} \mathrm{SiO}_{4}\right.$ ), enstatite (En; $\left.\mathrm{MgSiO}_{3}\right), \mathrm{MnS}, \mathrm{Na}_{2} \mathrm{~S}$, and $\mathrm{ZnS}$. With the exception of forsterite (not shown) and enstatite on Jupiter, all condensates shown here condense as solids. 


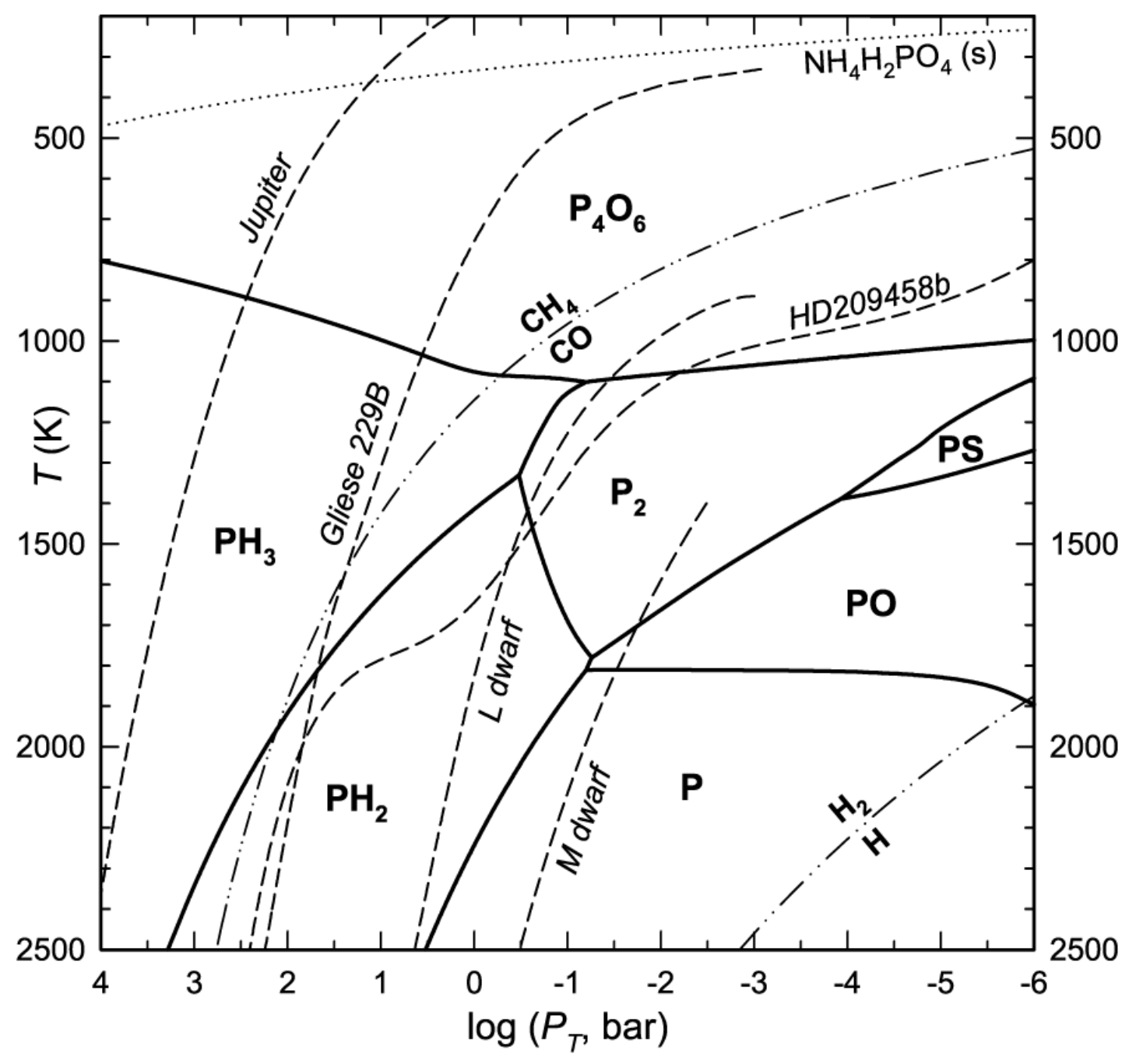

Fig. 4.- Overview of phosphorus chemistry as a function of temperature and pressure in a solar system composition gas. The solid lines indicate where major P-bearing gases have equal abundances. Also shown is the condensation curve for $\mathrm{NH}_{4} \mathrm{H}_{2} \mathrm{PO}_{4}$ (dotted line) and the position of the $\mathrm{H}_{2}=\mathrm{H}$ equal abundance boundary (dash-dot line). Atmospheric profiles for representative substellar objects are shown for reference (dashed lines). See text for details. 

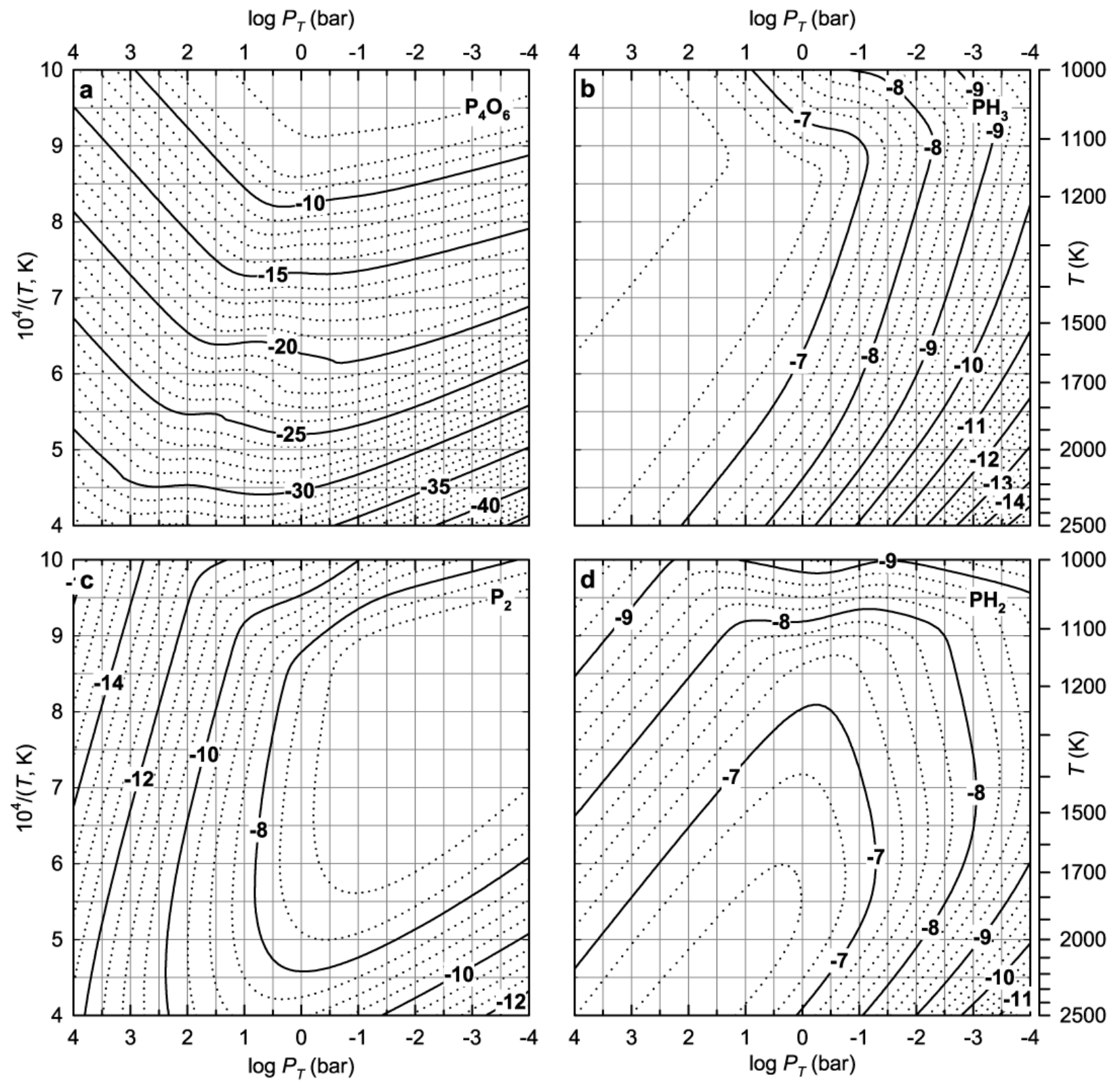

Fig. 5.- Mole fraction contours (on a logarithmic scale) for (a) tetraphosphorus hexaoxide $\left(\mathrm{P}_{4} \mathrm{O}_{6}\right)$, (b) phosphine $\left(\mathrm{PH}_{3}\right)$, (c) diatomic phosphorus $\left(\mathrm{P}_{2}\right)$, and (d) phosphino $\left(\mathrm{PH}_{2}\right)$ as a function of pressure and temperature in a solar metallicity gas. Gas abundances at higher or lower metallicities are given by the abundance expressions and/or the dependence on the metallicity factor $m$. 

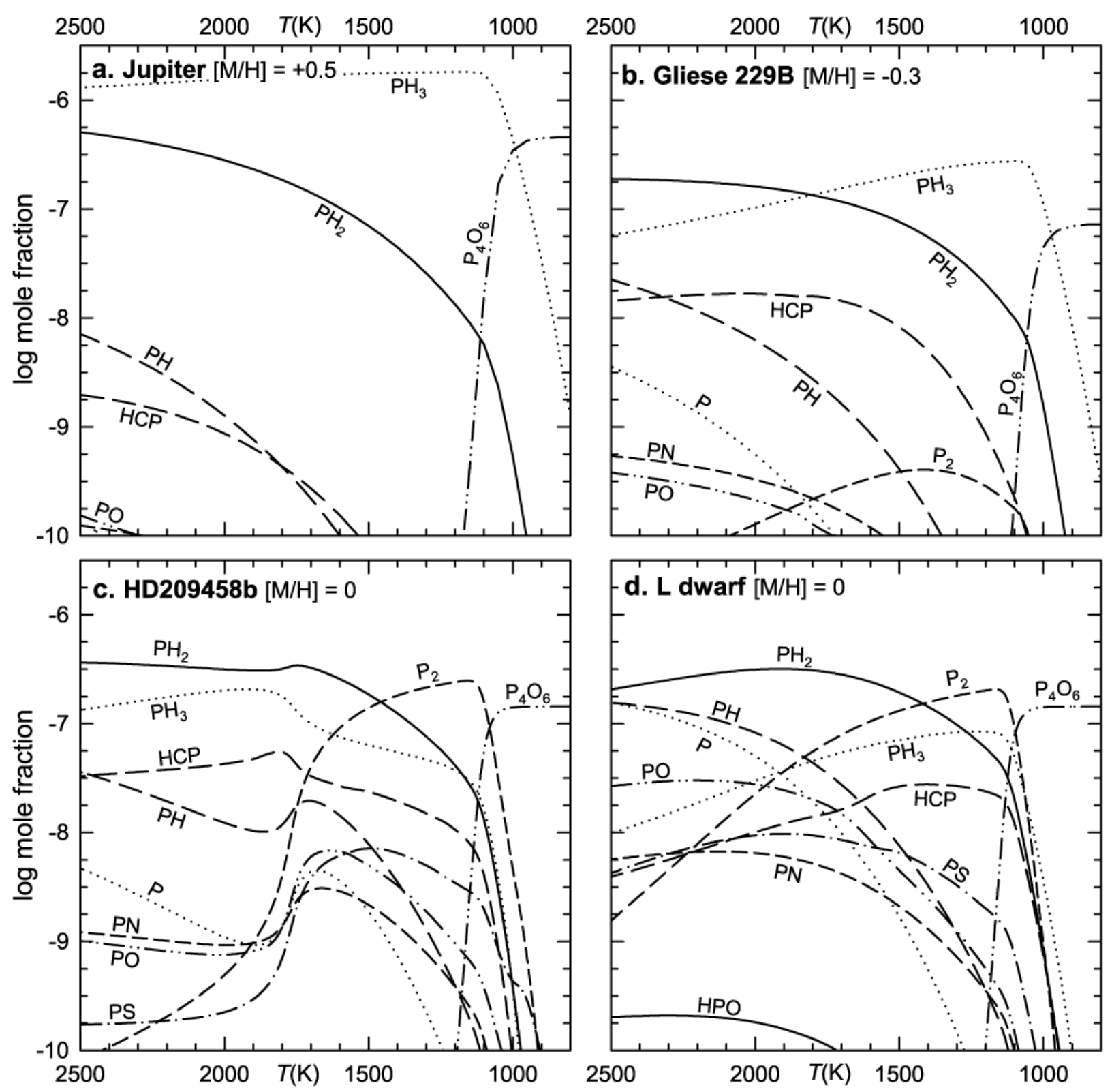

Fig. 6. - Phosphorus equilibrium chemistry along model atmosphere $P$ - $T$ profiles from 800 to $2500 \mathrm{~K}$ for $(\mathrm{a})$ Jupiter $\left([\mathrm{M} / \mathrm{H}] \approx+0.5 ; T_{\text {eff }}=124 \mathrm{~K}\right)$, (b) Gliese $229 \mathrm{~B}\left([\mathrm{M} / \mathrm{H}] \approx-0.3 ; T_{\text {eff }}\right.$ $=960 \mathrm{~K}),(\mathrm{c}) \mathrm{HD} 209458 \mathrm{~b}\left([\mathrm{M} / \mathrm{H}] \approx 0 ; T_{\text {eff }}=1350 \mathrm{~K}\right)$, and $(\mathrm{d})$ an $\mathrm{L} \operatorname{dwarf}\left([\mathrm{M} / \mathrm{H}] \approx 0 ; T_{\text {eff }}\right.$ $=1800 \mathrm{~K})$, assuming uniform elemental enrichments and depletions. Note that the $\mathrm{PH}_{3}$ to $\mathrm{P}_{4} \mathrm{O}_{6}$ conversion is kinetically inhibited in giant planets and $\mathrm{T}$ dwarfs, and that Jupiter's observable atmosphere lies outside the temperature range shown here. 


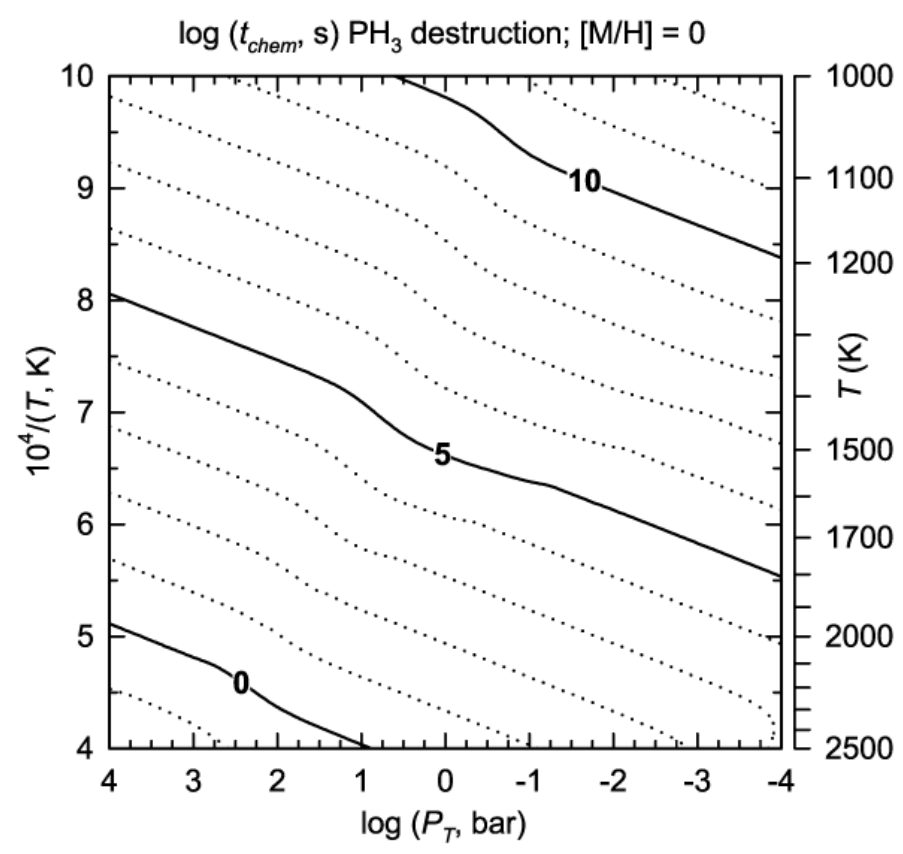

Fig. 7.- Logarithmic time scale (seconds) for the chemical conversion of $\mathrm{PH}_{3}$ to $\mathrm{P}_{4} \mathrm{O}_{6}$ in a solar metallicity gas. This conversion is kinetically inhibited in the upper atmospheres of giant planets and $\mathrm{T}$ dwarfs. 


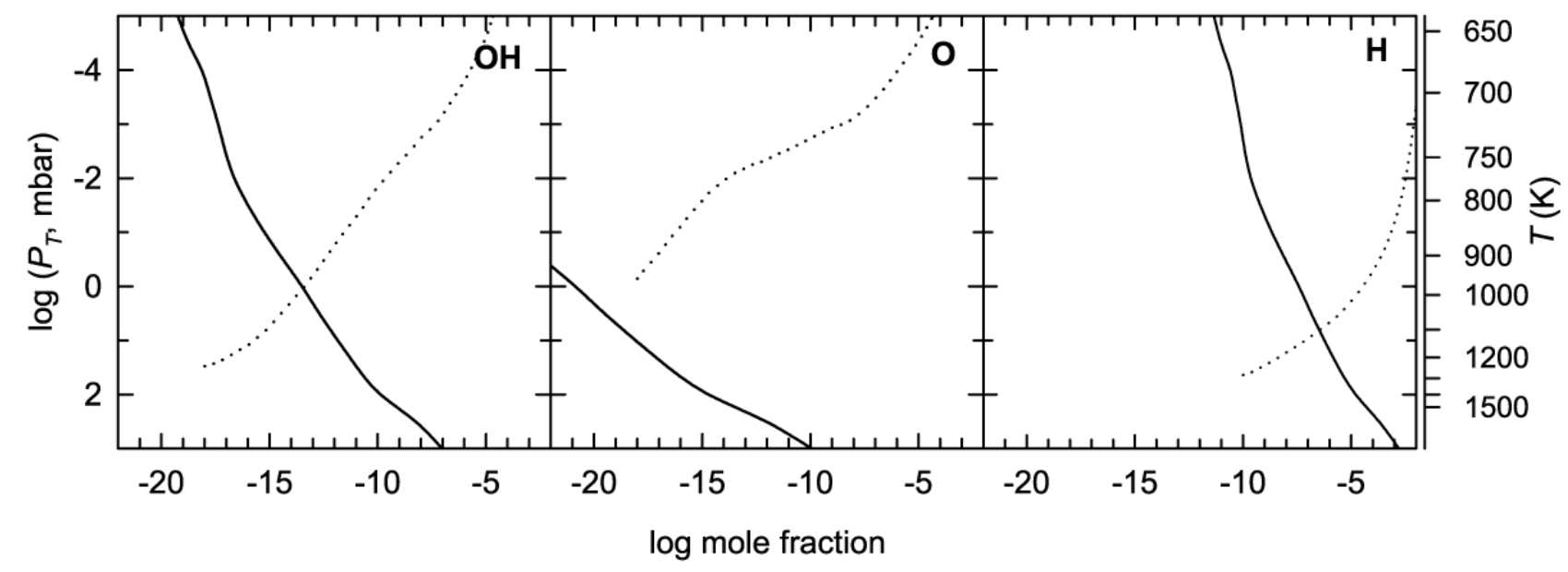

Fig. 8. - Comparison of thermochemical (solid lines) and photochemical (dotted lines; Liang et al. 2003) abundances for the reactive species $\mathrm{OH}, \mathrm{O}$, and $\mathrm{H}$ in the upper atmosphere of HD209458b. See text for details. 